\title{
Meat eaters by dissociation: How we present, prepare and talk about meat increases willingness to eat meat by reducing empathy and disgust
}

\author{
Jonas R. Kunst ${ }^{\text {a, b, * }}$, Sigrid M. Hohle ${ }^{c}$ \\ ${ }^{a}$ Department of Psychology, University of Oslo, Norway \\ b Department of Political Science and Government, University of Aarhus, Denmark \\ c Simula Research Laboratory, Oslo, Norway
}

\section{A R T I C L E I N F O}

\section{Article history:}

Received 8 April 2016

Received in revised form

1 July 2016

Accepted 6 July 2016

Available online 9 July 2016

\section{Keywords:}

Dissociation

Empathy

Disgust

Animals

Meat

Denial of mind

\begin{abstract}
A B S T R A C T
Many people enjoy eating meat but dislike causing pain to animals. Dissociating meat from its animal origins may be a powerful way to avoid cognitive dissonance resulting from this 'meat paradox'. Here, we provide the first comprehensive test of this hypothesis, highlighting underlying psychological mechanisms. Processed meat made participants less empathetic towards the slaughtered animal than unprocessed meat (Study 1). When beheaded, a whole roasted pork evoked less empathy (Study 2a) and disgust (Study $2 b$ ) than when the head was present. These affective responses, in turn, made participants more willing to eat the roast and less willing to consider an alternative vegetarian dish. Conversely, presenting a living animal in a meat advertisement increased empathy and reduced willingness to eat meat (Study 3). Next, describing industrial meat production as "harvesting" versus "killing" or "slaughtering" indirectly reduced empathy (Study 4). Last, replacing "beef/pork" with "cow/pig" in a restaurant menu increased empathy and disgust, which both equally reduced willingness to eat meat and increased willingness to choose an alternative vegetarian dish (Study 5). In all experiments, effects were strongly mediated by dissociation and interacted with participants' general dissociation tendencies in Study 3 and 5, so that effects were particularly pronounced among participants who generally spend efforts disassociating meat from animals in their daily lives. Together, this line of research demonstrates the large role various culturally-entrenched processes of dissociation play for meat consumption.
\end{abstract}

(C) 2016 Elsevier Ltd. All rights reserved.
Meat consumption is at an all-time high in the western hemisphere (OECD., 2014) and remains an inherent part of most people's diet (Ruby, 2012). Yet, many consumers experience what has been referred to as a "meat paradox" (Loughnan, Haslam, \& Bastian, 2010): They enjoy eating meat, but dislike causing pain to animals. To reduce this cognitive dissonance, omnivores may choose different strategies. For instance, they may adjust their behavior (e.g., by eating less meat), reduce their moral concern for animals (Bastian, Loughnan, Haslam, \& Radke, 2012; Loughnan et al., 2010), or find hedonistic, nutritional and evolutionary justifications to consume meat (Bohm, Lindblom, Åbacka, Bengs, \& Hörnell, 2015; Kubberød, Ueland, Tronstad, \& Risvik, 2002; Piazza et al., 2015; Rothgerber, 2013). A particularly effective way to solve this

\footnotetext{
* Corresponding author. Postboks 1094 Blindern, 0317 Oslo, Norway.

E-mail address: j.r.kunst@psykologi.uio.no (J.R. Kunst).
}

cognitive dissonance may, however, be even simpler: Consumers may simply dissociate meat from animals, that is, they may ignore or suppress the fact that the meat they eat originates from onceliving creatures (van Rijswijk, Frewer, Menozzi, \& Faioli, 2008).

Philosophers and animal rights activists have for long time emphasized the potency of disconnecting meat from animals as a strategy to deal with the meat paradox (e.g., Adams, 2004; Foer, 2010; Joy, 2011; Singer, 1995) and have taken for granted that it has profound effects on meat consumption. For instance, Hopkins and Dacey (2008) stated the following:

Modern American society loves to watch television cooking shows - the creativity, the sensuousness, the clever techniques. But chances are, if a lamb were dragged in and killed at the beginning of the program, most of the viewers would find themselves less interested in the lamb chop recipes. They would be too horrified or disgusted to enjoy the rest of the program. And yet, if the lamb's flesh is brought in already killed and sliced, 
almost all sense of horror and sympathy is muted enough to be nearly unfelt. (pp. 579-580)

Similarly, various public figures have argued that dissociation influences people's meat consumption. For instance, when Facebook founder Mark Zuckerberg decided to eat only meat he had slaughtered himself for one year, he publicly reasoned that "many people forget that a living being has to die for you to eat meat" (Zellers, 2011). Celebrity vegetarian Paul McCartney even more dramatically stated that "if slaughterhouses had glass walls, everyone would be a vegetarian” (PETA, 2013).

There is also empirical evidence suggesting that many consumers dislike when meat is not dissociated from its animal origin, and that they refrain from thinking about living animals when they buy or eat meat (Hoogland, de Boer, \& Boersema, 2005; Kubberød et al., 2002). Both vegetarians and non-vegetarians single out characteristics of meat revealing the animal's actual appearance such as raw meat, blood and other body parts as distressing (Beardsworth \& Keil, 1992; Hoogland et al., 2005; Kenyon \& Barker, 1998; Kubberød et al., 2002). Red meat is reported as being especially disgusting by women in particular (Beardsworth \& Keil, 1992; Kenyon \& Barker, 1998; Kubberød et al., 2002; Santos \& Booth, 1996), and when people move into vegetarianism they typically begin with avoiding red meat (Beardsworth \& Keil, 1992; Kenyon \& Barker, 1998; Santos \& Booth, 1996). Moreover, types of flesh that are "de-animalized", such as hamburgers, are often popular meat products (Kubberød et al., 2002).

Although dissociation is shown to be common in the Western world, and its effect on meat consumption is taken for granted in scholarly and public discourse, a comprehensive empirical test of the factual effects of dissociation is missing at present. In this paper, we therefore aim to empirically demonstrate how the ways we present, talk about and prepare meat in contemporary modern societies make dissociation a powerful, culturally-entrenched strategy for people to avoid the dissonance that results from the meat paradox. The effects of dissociation on meat eating we expect to be substantially mediated by empathy and disgust.

\section{Dissociation through processing, omission and euphemisms}

Earlier generations of humans were often familiar with individual characteristics of the animals they ate as well as the way animals were treated (Foer, 2010). Yet, as the traditional family farm has been vastly replaced by large-scale corporate farming in many, if not most, parts of the world (Magdoff, Foster, \& Buttel, 2000), the majority of omnivores have steadily less contact with the living animals they consume (Leroy \& Degreef, 2015). Animals were in fact among the earliest part of the modern diet to be distanced from consumers. Owing to power saws, acute division of labor, and more efficient transport and preservation, most consumers no longer witness food animals' lives and deaths (Belasco, 2008).

In addition to being uninvolved in the process of killing animals per se, consumers seldom take part in later processing steps that remove typical animal characteristics from the dead corpus (Lerner \& Kalof, 1999). These steps include beheading, the removal of entrails, plucking, and cutting of animal bodies into consumerfriendly pieces and portions as we see them in the supermarket. As a consequence, popular meat products such as 'minced' or 'ground' meat hardly resemble the original animal host (Leroy \& Degreef, 2015). For the average consumer that did not take part in these steps, buying meat at a late stage of processing should therefore facilitate the process of dissociation (Kubberød et al., 2002).
Second, both the treatment of animals and the system that transforms animals into meat are rendered invisible by the visual representation of meat products (Rogers, 2008). For instance, while cows are often displayed in dairy advertisement, they are less common in advertisement of beef products (Grauerholz, 2007; Heinz \& Lee, 1998). Regardless of whether this presentation strategy is consciously or unconsciously adopted by the meat industry, the fact that knowing about food products' origin can predict their rejection (Rozin \& Fallon, 1980) makes it likely that omitting cues of animal origins from advertisements facilitates the process of dissociation.

Third, dissociation can also be observed at the linguistic level. Living animals are called cows, pigs, and calves, but once dead and prepared for food they become beef, pork and veal (Adams, 2004; Dunayer, 2001; Singer, 1995), with the consequence that a direct reference to the animal origins of meat is linguistically blurred (Heinz \& Lee, 1998). In a similar manner, the way the food industry talks about their large-scale killing of animals may sustain the process of dissociation. "Meat plants" and "meat factories" are often used as euphemisms for "butchery" and "slaughterhouse", and draw the attention away from the animals that are killed (Serpell, 1986). Likewise, the use of terms such as "harvesting" to refer to the killing of animals may dissociate meat from the animal origin by equating it with plants (Stibbe, 2001).

\section{Dissociation and meat consumption: the mediating role of empathy and disgust}

Although experimental evidence is lacking, there is some correlational support for the notion that dissociation predicts less willingness to eat meat. Rothgerber (2013) showed that trait dissociation, that is, a general tendency to avoid associating meat with animals, was related to lower meat consumption and that this tendency may be higher among people who generally refrain from eating meat (Rothgerber, 2015). While there is little evidence linking dissociation to meat eating, no study has to our knowledge investigated the underlying affective processes of dissociation. We argue that a decrease in empathy towards animals and suppression of feelings of disgust associated with dead animals are likely to mediate such effects.

Empathy is not an exclusively inter-human phenomenon and emerging evidence suggest that humans are evolutionary predisposed also for empathy towards non-human animals (Phillips, 2009; also see; Filippi et al., 2010). Possibly because it offers an adaptive advantage to show compassion for animals that humans depend on, this empathy is especially pronounced towards domesticated animals (Leak \& Christopher, 1982). In fact, people's subjective and physical empathic responses towards human and non-human animals are of comparable strength (Westbury \& Neumann, 2008). Moreover, empathy measured as a general construct as well as explicitly framed towards animals was negatively related to meat consumption in previous research (Cerjak, Karolyi, \& Mesić, 2011; Rothgerber \& Mican, 2014), and is likely to mediate the effects of dissociation on attitudes towards meat consumption. In other words, because dissociation essentially removes the cognitive connection between meat and animals, it should reduce the degree to which people feel empathy towards animals, which, in turn, should sustain their willingness to eat meat.

Second, we assume dissociation to bolster meat consumption because it suppresses feelings of disgust. One function of the core emotion disgust is to protect the individual from contamination with pathogens and here especially within contexts that involve "dead bodies, rotting foods, and bodily fluids" (Tybur, Lieberman, \& Griskevicius, 2009, p. 105). Indeed, disgust plays a major role for 
food choice, especially towards food products from animal origins as these bear the highest risk of contamination (Rozin \& Fallon, $1980,1987)$. Because interrupting the process of dissociation essentially reminds consumers of the fact that they are eating potentially contaminated carcasses, this should result in feelings of disgust that, in turn, are linked to less meat eating. As a result, disgust should mediate the effect of dissociation on willingness to eat meat.

\section{The present research}

The aim of this research was to present the first comprehensive experimental test of the dissociation hypothesis and its underlying processes across a range of scenarios using real-world stimuli. Specifically, in five experiments, we aim to empirically demonstrate 1) how daily life processes of dissociation reduce empathy and disgust, and 2) thereby increase willingness to eat meat (see Table 1 for an overview over the studies). Moreover, we aim to demonstrate the potency of these processes by comparing them to alternative processes such as reduced attribution of mind to animals (Loughnan et al., 2010).

Throughout, we use the term 'state dissociation' to refer to dissociation as response to specific experimental stimuli, while we use 'trait dissociation' to refer to individual differences in participants' general dissociation tendencies. In the first study, we test whether processing of meat leads to less empathy towards the animal that was killed as a result of more state dissociation. Next, we test whether the removal of the head from an animal roast increases state dissociation, leading to less empathy (Study 2a) and less empathy and disgust (Study 2b). Here, we also test whether this reduction in empathy and disgust, in turn, increases willingness to eat the meat and decreases the likelihood that participants consider a vegetarian alternative dish. In Study 3, we test whether presenting a living lamb in a lamb chop advertisement would reduce state dissociation and thereby lead to more empathy and less willingness to eat meat. In this study, we also test whether such an effect is particularly apparent among individuals who generally strive to dissociate animals from meat and, hence, score high on trait dissociation.

Moving to linguistic aspects of dissociation, we in Study 4 test whether using the euphemism "harvesting" to refer to the largescale killing or slaughter of animals by the meat industry would increase state dissociation with consequent effects on empathy. Finally, in Study 5, we test whether presenting meat ingredients in a restaurant menu as "cow" and "pig" instead of "beef" and "pork" would interrupt the process of state dissociation, leading to more empathy and disgust and, consequently, to less willingness to eat a meat dish and more willingness to consider a vegetarian alternative. Again, we here test whether this process is especially apparent among individuals who score high on trait dissociation and, hence, generally try to dissociate meat from animals.

To test whether the effects can be generalized and are not specific to one animal type, a variation of animals (chicken, pig, cow and sheep) are included as stimuli in the different studies. In terms of our analytic procedure, in all studies we conduct between-group comparisons using IBM SPSS version 22, while path analyses with manifest variables were conducted in IBM AMOS version 22 to test for mediation. Last, the PROCESS macro (Hayes, 2013) was used to test whether experimental effects were moderated by trait dissociation in Study 3 and 5.

\section{Study 1}

The average consumer can choose between wide varieties of meat products. One dimension on which these products differ is the degree to which they are industrially processed. For instance, consumers can buy a relatively unprocessed whole raw chicken that still resembles the animal's shape and structure to some degree, or minced chicken meat that has no resemblance to this shape or structure at all. In this first study, we hypothesize that the more industrially processed meat is, the less empathy it elicits towards the animal that was slaughtered. This effect we expect to be due to state dissociation. That is, we predict that participants who see the industrially processed meat show less empathy because they have more difficulties imagining that the meat came from a living being.

\subsection{Method}

\subsubsection{Participants}

A total of 288 native Norwegians were recruited through snowball sampling on social online networks for a study on the "perception of pictures". The majority of participants were women $(61.1 \%)$ and the average age was 30.86 years $(S D=11.58)$. While $92.4 \%$ reported to be omnivores, 3.5\% reported to be pescetarians, $2.8 \%$ to be vegetarians and $1.4 \%$ to be vegan. On a scale ranging from 0 (never) to 7 (daily), participants on average reported to eat meat 5.13 days $(S D=2.03)$. Asked about how often they ate chicken specifically, they reported to eat this type of meat 1.39 days per week $(M=1.04)$.

\subsubsection{Procedure}

Participants were randomly assigned to one of three conditions. In each condition, participants answered the same set of questions related to a picture of raw chicken meat that was presented on top of the screen. Crucially, we experimentally varied the degree to which the meat had been industrially processed. That is, in the low processing condition that was treated as control group, the picture displayed a whole chicken (see Table 1 for the three pictures). In the medium processing condition, it displayed a chicken that had been cut into commonly consumed parts. In the high processing condition, the picture showed minced chicken meat. The pictures were matched in color and size and were in each condition displayed on top throughout the survey (except on the informed consent page and the demographic section where no picture was presented). While seeing the picture on top, participants completed the following measures:

\subsubsection{Empathy}

Five questions, of which two were reversed to prevent response bias, measured empathy for the animal that had been slaughtered $(\alpha=0.93)$. These items were based on the empathy subscale of the interpersonal reactivity index developed by Davis (1980), but were adjusted for the purpose of the present research. Specifically, on a 7-point Likert scale ranging from 1 (totally disagree) to 7 (totally agree), participants rated their agreement with the statements "When I see the picture above, I feel sorry for the animal that was slaughtered", "Thinking about the animal that was slaughtered to produce the meat displayed above does not disturb me a great deal" (reversed), "Seeing the picture makes $\overline{\text { me }}$ feel pity for the animal that was slaughtered", "I feel sad for the animal that died to produce the meat above" and "I do not really feel very sorry for the animal that had to die" (reversed).

\subsubsection{State dissociation}

Three items measured the degree of dissociation in response to the stimuli. Specifically, participants rated their agreement with the statement "The first thing I thought about when I saw the picture above was a living being" on the same Likert scale as the empathy measure. Next, they rated how difficult or easy they found it to imagine that what was "displayed on the picture once was part of a 
Table 1

Hypotheses, main study variables and stimuli used in the different studies are displayed.

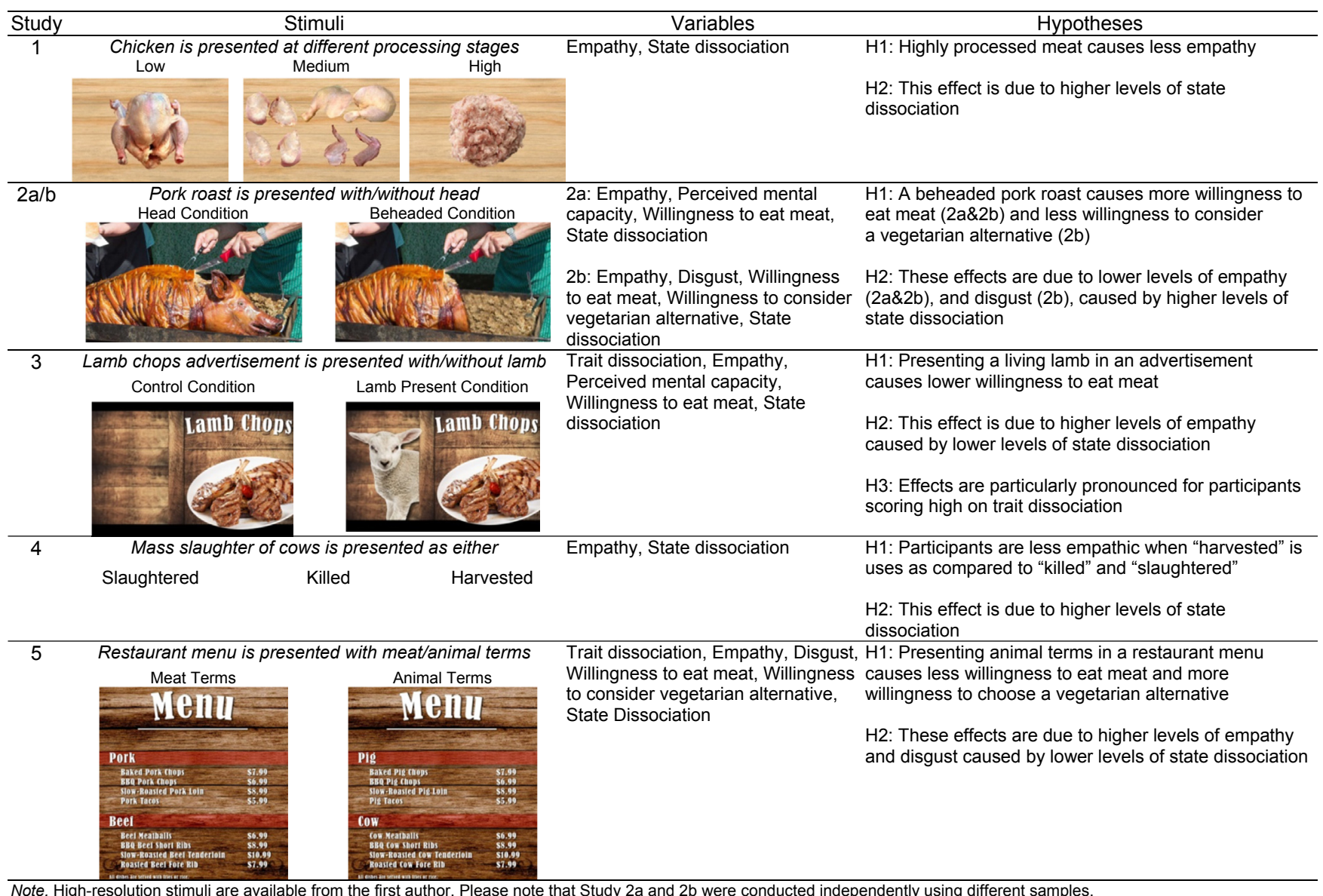

Note. High-resolution stimuli are available from the first author. Please note that Study $2 \mathrm{a}$ and $2 \mathrm{~b}$ were conducted independently using different samples. 
living being" on a 7-point scale ranging from 1 (very difficult) to 7 (very easy). Last, they completed the question "How much does the picture above remind you of a living being?" where responses were rated on a 7-point scale ranging from 1 (not at all) to 7 (very much). The scale comprising these three items had acceptable reliability $(\alpha=0.68)$ and scores were reversed so that higher scores meant more state dissociation.

\subsection{Results}

In a multivariate analysis of variance (MANOVA) with empathy and state dissociation as dependent variables, the experimental manipulation had a multivariate effect, $F(4,570)=11.64, p<0.001$, $\eta_{\mathrm{p}}^{2}=0.08$. This effect did not further interact with participants' gender $(p=0.892)$. Planned contrasts showed that participants in the high processing condition indeed showed more state dissociation $(M=5.33, S E=0.13)$ than in the low processing condition $(M=4.10, S E=0.14 ; p<0.001,95 \% \mathrm{CI}$ of difference $[0.85,1.61])$. No difference was observed between the medium processing condition $(M=4.27, S E=0.13)$ and the low processing condition $(p=0.379)$. Planned contrasts showed that participants in the high processing condition also reported less empathy towards the animal that was slaughtered $(M=2.91, S E=0.17)$ than those in the low processing condition $(M=3.41, S E=0.18 ; p=0.045,95 \% \mathrm{CI}$ of difference $[-0.98,-0.01])$. Although an inspection of the error bars (see Fig. 1) suggested that participants in the medium processing condition tended to show less empathy than those in the low processing condition, this difference was insignificant ( $p=0.465$ ).

Next, we set out to test whether the lower empathy in the high processing condition compared to the low processing condition was due to, and hence mediated by, state dissociation. To do so, we estimated a path model where state dissociation mediated the effect of the experimental condition (coded as: $0=$ low processing, 1 = high processing) on empathy. Indeed, in this fully-saturated model, state dissociation fully mediated the effect of the experimental manipulation on empathy (see Fig. 2). Bootstrapping with 5000 random re-samples showed that the resulting, indirect effect was negative and significant $(\beta=-0.22, S E=0.05,95 \% \mathrm{CI}[-0.32$, $-0.14], p<0.001)$.

\subsection{Preliminary discussion}

As expected, the degree to which raw chicken meat is industrially processed predicted different degrees of empathy. Importantly, these effects were fully due to state dissociation, supporting

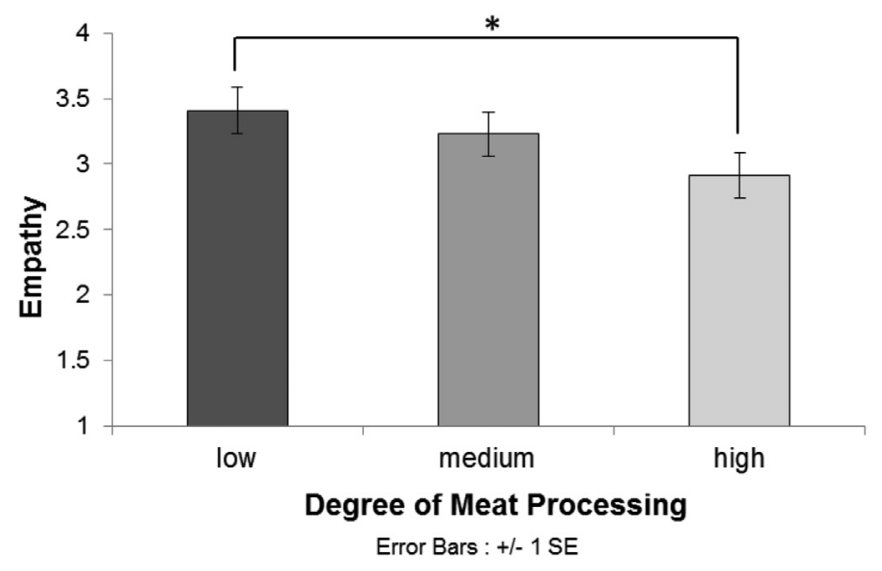

Fig. 1. In Study 1, participants reported less empathy towards the animal that was slaughtered in the high processing condition than in the low processing condition. ${ }^{*} p<0.05 . \pm 1$ SE are displayed.

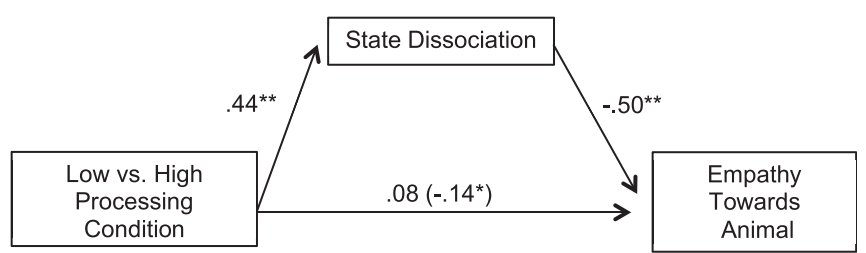

Fig. 2. Dissociation fully mediated the effect of the experimental condition on empathy in Study 1. The estimate in parenthesis represents the direct effect before the mediator was added to the model. Standardized estimates are displayed. ${ }^{*} p=0.054$, ** $p<0.001$.

its importance as underlying process. Nevertheless, although providing first support for our hypothesis, the study had some limitations. First, even the baseline picture showed a relatively processed and beheaded hen. Previous research suggests that the face is "the emotion highway" (De Waal, 2009, p. 83), communicating inner states and offering the quickest connection to the other. It may therefore be necessary to evoke empathy (Cole, 2001). Hence, especially the removal of the head may potentiate the dissociation - empathy link. Second, empathy increases with similarity, and here species similarity is one relevant factor (Brown, Bradley, \& Lang, 2006; Krebs, 1975; Preston \& de Waal, 2002). For instance, humans generally feel more empathy towards other primates and mammals, and less empathy towards birds (Kubberød et al., 2002; Westbury \& Neumann, 2008). Hence, the observed effects may have been stronger if we had used another animal, such as a pig or a cow. The next study addresses these limitations.

\section{Study 2a}

In this study, we test whether removing the head from an otherwise identical animal roast would produce less empathy and more willingness to eat meat. It has been suggested that people solve the meat paradox by downplaying the perceived mental capacity of animals they eat (Bastian, Loughnan, et al., 2012; Loughnan et al., 2010). Such a rationalization process is likely to be more difficult when the animal head is present as it is the center of mental capacities. Hence, while we expect the effects of removing the head on empathy and willingness to eat meat to be mediated by state dissociation, we also test perceived mental capacity as alternative mediator (Bastian, Loughnan, et al., 2012; Loughnan et al., 2010).

\subsection{Method}

\subsubsection{Participants}

We recruited 168 US Americans through Amazon MTurk. As in all of the remaining studies, the research was described as dealing with "social issues and food". The average age was 32.89 years $(S D=10.16)$ and both genders were relatively equally distributed (women: 43.5\%). Of all participants, $89.3 \%$ reported to be omnivores, $6.0 \%$ reported to be pescetarians, $3.0 \%$ to be vegetarians and $1.8 \%$ to be vegan. On average, participants reported to eat meat in general including fish 5.08 days per week $(S D=2.13)$, and pork 1.52 days per week $(S D=1.36)$.

\subsubsection{Procedure}

Participants were randomly assigned to one of two conditions. In both conditions, they were told that they were about to see a picture of a pork roast. In the head condition, the pig's head was visible, whereas it was removed with a photo-editing software in the beheaded condition. Apart from this difference, the picture was identical (see Table 1 for the stimuli). As in the first study, the 
picture was presented on top throughout the survey, except in the demographics section and the informed consent form. In addition to the empathy $(\alpha=0.98)$ and state dissociation measure $(\alpha=0.75)$ from Study 1, participants also completed a capacity for sensation measure and indicated their hypothetical willingness to eat the meat:

\subsubsection{Capacity for sensation}

A measure adopted from Bastian, Costello, Loughnan, and Hodson (2012) was used to assess attribution of mind to the animal that had been killed. Specifically, participants rated the degree to which they believed that the animal once had the mental capacity to experience nine sensations (i.e., pain, hunger, pleasure, fear, happiness, consciousness, seeing, hearing, tasting; $\alpha=0.95$ ) and nine intellectual states (i.e., thinking, imagining, wishing, needing, desire, intending, planning, choosing, reasoning; $\alpha=0.94$ ) on 7-point scales ranging from 1 (definitely did not experience) to 7 (definitely did experience).

\subsubsection{Willingness to eat meat}

Participants answered to the following question: "Hypothetically speaking, how negative or positive do you feel about eating the meat on the picture?" Responses were rated on a slidingresponse scale ranging from 0 (extremely negative) to 100 (extremely positive).

\subsection{Results}

The beheaded condition produced a substantial drop in empathy, $t(166)=4.94, p<0.001$, increased state dissociation, $t(166)=-7.52, p<0.001$ (see Fig. 3) and willingness to eat the meat, $t(166)=-3.83, p<0.001$ (see Fig. 4). No effect was observed on the sensation, $t(166)=1.07, p=0.258$, or intellectual capacity measures, $t(166)=0.92, p=0.361$. None of the effects was moderated by gender $(0.399<p s<0.830)$.

We set out to test whether 1) state dissociation would mediate the effect on empathy and 2) whether the effect on willingness to eat the meat would be mediated by this lowered empathy that resulted from state dissociation. To do so, we ran a saturated path model with experimental manipulation as predictor, state dissociation as first stage mediator, empathy as second stage mediator

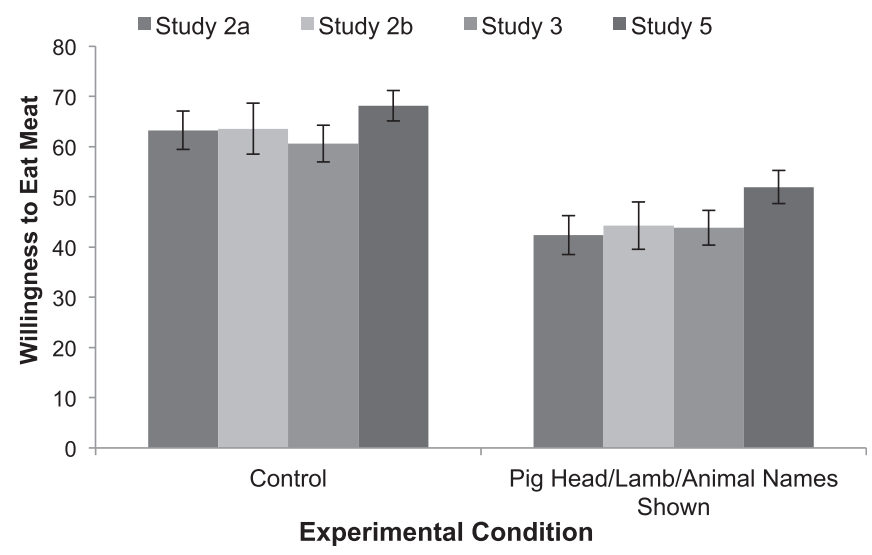

Fig. 4. Showing the head of the pig (Study 2a and 2b), a living lamb (Study 3) or replacing "beef" with "cow" and "pork" with "pig" in a restaurant menu (Study 5) made participants feel less willing to eat meat. \pm 1 SE are displayed.

(predicted by state dissociation), and willingness to eat meat as outcome variable. Indeed, once we added state dissociation to the model, the direct effects on empathy and willingness to eat meat became insignificant, indicating full mediation (see Fig. 5). Bootstrapping indicated that the resulting indirect effects of the experimental manipulation on empathy $(\beta=-0.35, S E=0.06,95 \%$ $\mathrm{CI}[-0.48,-0.25], p<0.001)$ and on willingness to eat meat were significant $(\beta=0.25, S E=0.06,95 \% \mathrm{CI}[0.13,0.38], p<0.001)$.

\subsection{Preliminary discussion}

As expected, beheading the pork roast strongly reduced empathy, and this relation was fully due to an increase in state dissociation. Moreover, the decrease in empathy caused by heightened dissociation fully mediated the effect on willingness to eat meat. In other words, participants seemed more willing to eat the meat when the head was removed precisely because it increased state dissociation and thereby led to less empathy. No effect was observed on the mental capacity ratings, even though the head is the locus of mental capacity. Hence, the results lend support for dissociation being the dominant process here.
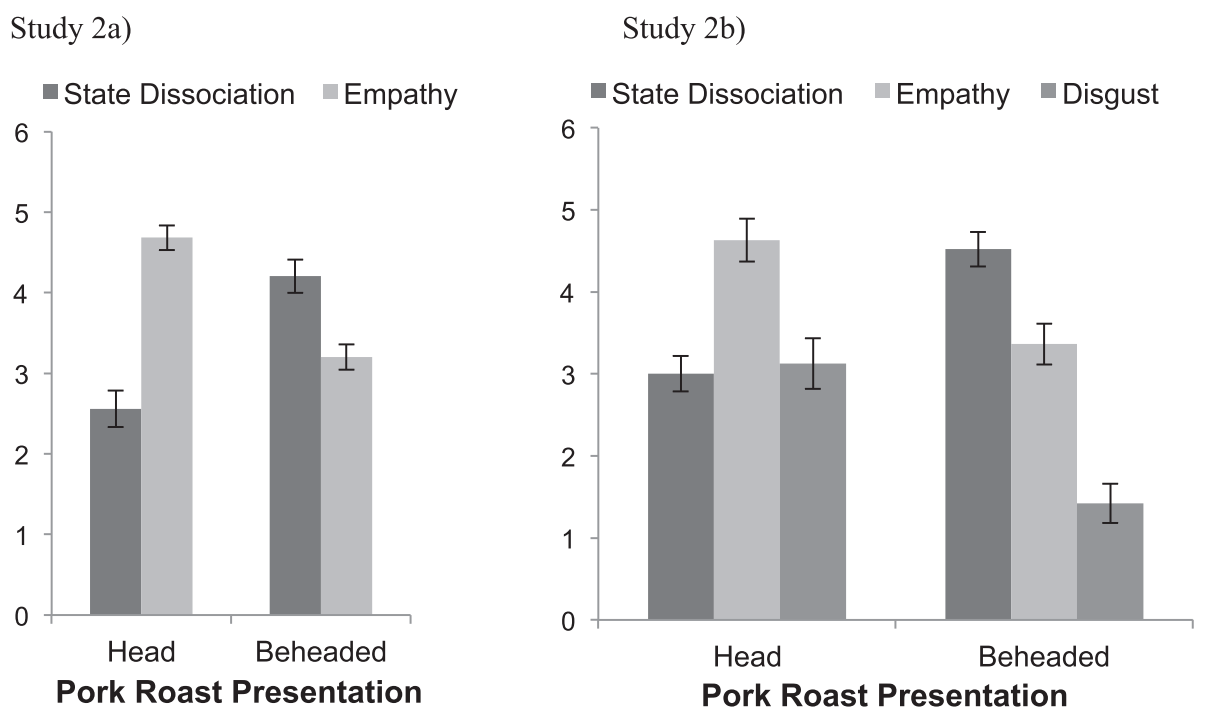

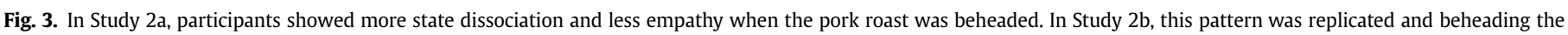
pork roast also decreased feelings of disgust. \pm 1 SE are displayed. 

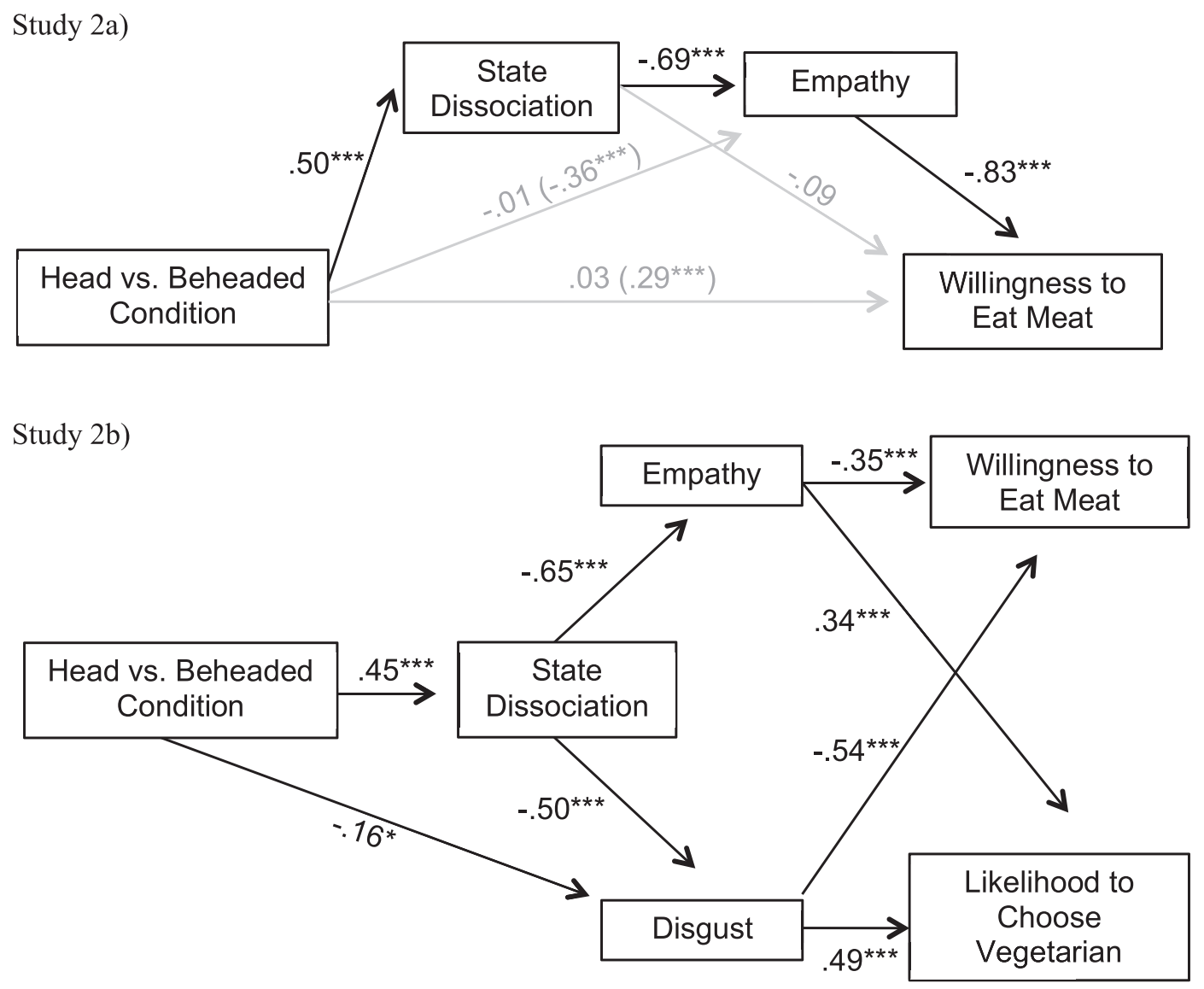

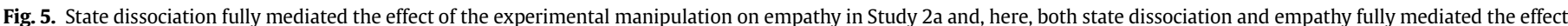

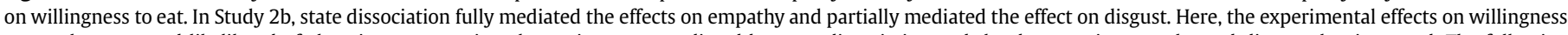

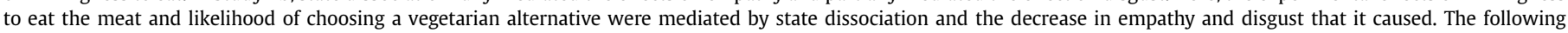

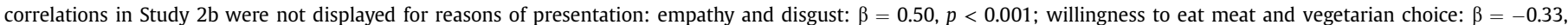
$p<0.001$. ${ }^{*} p<0.05,{ }^{* * *} p<0.001$. Standardized estimates are displayed.

While supporting our predictions, this study was limited as it did not include disgust as alternative mediator. In the next study, we therefore try to replicate our findings testing the unique role of both mediators.

\section{Study $2 b$}

\subsection{Method}

\subsubsection{Participants}

Power analyses conducted in GPower 3.1 and based on betweengroup differences with the effect size $d$ of around 0.70 observed in Study 2a indicated that 90 participants would be needed to have a $95 \%$ chance to observe an effect with a significance criterion of 0.05 . This sample size also satisfies the recommended ratio of five to ten participants per observed variable for structural equation modelling (Bentler \& Chou, 1987). To ensure adequate power, we recruited 101 participants $\left(M_{\text {age }}=34.80, S D_{\text {age }}=11.40\right.$; women: $60.4 \%$ ) using the same approach as in Study 2a. In this sample, $87.0 \%$ reported to be omnivores, $7.0 \%$ to be pescetarians and $6.0 \%$ to be vegetarians. On average, participants reported to eat meat 4.63 days per week $(S D=2.39)$ and pork specifically 1.29 days per week $(S D=1.05)$.

\subsubsection{Procedure}

Following the exact procedure as in the previous study, participants were randomly assigned to the head or beheaded condition. Seeing the respective pork roast picture, participants completed the same measures as in the previous study (empathy: $\alpha=0.96$; state dissociation: $\alpha=0.81$; willingness to eat meat), with the difference that they also were asked to indicate how likely it was that they would choose an alternative vegetarian dish on a sliding-response scale ( 0 very unlikely - 100 very likely). Moreover, they completed a measure of disgust adopted from Horberg, Oveis, Keltner, and Cohen (2009) instead of the capacity of sensation measure, as the latter was unaffected by the experiment in Study 2a. Here, participants rated the degree to which they felt three emotions (i.e., "grossed out", "disgusted" and "queasy, sick to my stomach"; $\alpha=0.97$ ) when they saw the picture on a 7-point scale, ranging from 0 (not at all) to 6 (a great deal).

\subsection{Results}

Participants showed more state dissociation, $t(99)=-5.04$, $p<0.001$, less empathy, $t(99)=3.51, p=0.001$, and less disgust, $t(99)=4.32, p<0.001$, when the pork roast was beheaded than when the head was part of the roast (see Fig. 3). Moreover, they showed a higher willingness to eat the meat, $t(99)=-2.77$, $p=0.007$ (see Fig. 4), and were marginally significantly less likely to consider a vegetarian alternative-with head: $M=52.00$, $S E=5.56$; beheaded: $M=37.88, S E=5.11 ; t(99)=1.87, p=0.065$. Neither of these effects was further moderated by participants' 
gender $(0.156<p s<0.580)$.

Next, we estimated a path model similar to Study 2a. However, given the more complex model with two mediators and the smaller sample size, we tested a more parsimonious model, dropping the direct effects that turned insignificant when mediators were added to the model in the previous studies. Hence, based on our working hypotheses and the full mediations observed in the previous two studies, state dissociation was expected to fully mediate the experimental effects on empathy and at least partially to mediate the effects on disgust, given that we still had no evidence about the strength of the latter mediation. Moreover, as empathy (predicted by state dissociation) had fully mediated the experimental effects on willingness to eat meat, we expected empathy and disgust together also to fully mediate these effects. In the well-fitting model, $\chi^{2}(d f=5, N=101)=8.34, p=0.138$, RMSEA $=0.082$, $\mathrm{CFI}=0.991$, bootstrapping showed that the experimental manipulation indirectly led to less empathy ( $\beta=-0.29, S E=0.06,95 \% \mathrm{CI}$ $[-0.43,-0.17], p=0.001)$ and disgust $(\beta=-0.22, S E=0.07,95 \% \mathrm{CI}$ $[-0.36,-0.12], p<0.001)$, mediated by state dissociation. When considering a weak direct effect of the experimental manipulation on disgust that remained significant $(\beta=-0.16, p=0.049)$, the total effects of the experimental manipulation on disgust and empathy did not differ in strength $(\Delta \beta=0.09, S E=0.07,95 \% \mathrm{CI}[-0.06,0.23])$.

Because empathy and disgust predicted less willingness to eat meat and a higher likelihood to choose the vegetarian alternative, the experimental manipulation had an indirect positive effect on willingness to eat the meat ( $\beta=0.31, S E=0.07,95 \% \mathrm{CI}[0.18,0.45]$, $p<0.001$ ) and an indirect negative effect on likelihood to choose vegetarian $(\beta=-0.29, S E=0.06,95 \% \mathrm{CI}[-0.41,-0.18], p<0.001)$. The indirect effects that involved mediation by empathy did not differ in strength from those that involved mediation by disgust (willingness to eat meat as dependent variable: $\Delta \beta=-0.10$, $S E=0.07,95 \% \mathrm{CI}[-0.26,0.03]$; likelihood to choose vegetarian as dependent variable: $\Delta \beta=0.09, S E=0.07,95 \% \mathrm{CI}[-0.03,0.25]$ ).

\subsection{Preliminary discussion}

We successfully replicated the findings from Study 2a, while also obtaining first evidence of disgust functioning as additional mediator. As expected, both disgust and empathy to equal degrees mediated the effects of state dissociation on willingness to eat meat and on likelihood to choose a vegetarian alternative dish. Thus, the removal of the head seems crucial in making consumers disconnect meat from its animal origin, with downstream effects on disgust, empathy and, consequently, meat eating.

\section{Study 3}

It is not unusual that animals are presented alongside the advertisement for agricultural products that do not involve the killing of an animal (e.g., cows in a milk advertisement). However, when the killing of an animal is involved as in the production of meat, this is seldom the case (Grauerholz, 2007; Heinz \& Lee, 1998). In this study, we hypothesize and test whether portraying a living animal in a meat advertisement increases empathy because it interrupts the underlying dissociation process and, as a consequence of this effect, decreases willingness to eat the respective meat.

Having established a general pattern of results in the two first studies, we also test whether these effects interact with individual differences in dissociation. In fact, the degree to which people mentally separate meat from its animal origin seems to result not only from features of the meat product, as indicated by Studies 1 and 2, but also from individual differences in dissociation (Rothgerber, 2013). Reports indicate that a considerable percentage of meat consumers do not like to think about the fact that the meat they consume comes from once-living animals (Mayfield, Bennett, Tranter, \& Wooldridge, 2007), and avoid to associate meat with animals in order to draw attention away from the act of eating animals. Using a trait measure of this tendency, we test whether variations in trait dissociation moderate the experimental effects. High dissociation tendency is linked to lower meat consumption (Rothgerber, 2013), such that people who generally tend to spend efforts dissociating animals from meat consume less meat. If the presence of a living animal in the advertisement renders dissociation more difficult, we hypothesize this effect to be especially pronounced among individuals with high trait dissociation, as they already struggle with dissociating meat from animals. Such a moderated effect would give even stronger support of the role of dissociation for meat consumption.

Last, because it has been argued that denying animals morally relevant qualities may be a potent way to resolve the meat paradox especially in scenarios where animals are presented in meat advertisements (Bastian, 2011), we again include such as measure as alternative mediator despite the fact that no such effects were observed in Study 2a.

\subsection{Method}

\subsubsection{Participants}

Following the same procedure as in the previous study, 187 US Americans were recruited through Amazon MTurk $\left(M_{\mathrm{age}}=37.32\right.$, $S D_{\text {age }}=13.49 ; 56.7 \%$ women). While $90.4 \%$ reported to be omnivores, $3.2 \%$ were pescetarians, $4.8 \%$ vegetarians and $1.6 \%$ vegans. On average, participants reported to eat meat 4.75 days per week $(S D=2.16)$ and lamb specifically 0.28 days per week $(S D=0.77)$.

\subsubsection{Procedure}

Participants first completed a moderator measure assessing their general disassociation tendencies (see description of this measure below). Next, they finished three filler tasks and were told that they would be asked questions about an advertisement, before being randomly assigned to one of two conditions. In both conditions, a lamb chops advertisement was presented on top of the survey. However, in the control condition, only the lamb chops were presented on the picture, whereas a picture of a living lamb was added to the advertisement in the lamb condition (see Table 1 for the stimuli). The size and design of the advertisement were carefully matched between conditions. Participants were asked to complete the following measures ${ }^{1}$ (note that the "advertisement" picture was only displayed for mediators and dependent variables and not for the trait dissociation moderator):

\subsubsection{Trait dissociation}

We used a scale from Rothgerber (2013) to measure general tendencies to dissociate animals from meat ( $\alpha=0.88$ ). Specifically, participants completed three items such as "When I look at meat, I try hard not to connect it with an animal" or "When I eat meat, I try not to think about the life of the animal I am eating" where responses were rated on a 7-point Likert scale ranging from 1 (totally disagree) to 7 (totally agree).

\subsubsection{Empathy}

The five items used to measure empathy in the previous studies were adapted to the present context (i.e., "Seeing the lamb chops makes me feel pity for the animal that was slaughtered"; $\alpha=0.96$ ).

\footnotetext{
1 The survey contained one exploratory measure, tapping food associations, that was not included in the analyses as it was irrelevant for the focus of this paper.
} 


\subsubsection{Capacity for sensation}

As in Study 2a, the measure of Bastian, Costello, et al. (2012) was used to assess attribution of mind (sensation subscale: $\alpha=0.92$; intellect subscale: $\alpha=0.92$ ).

\subsubsection{Willingness to eat}

As in the previous study, participants indicated how positive or negative they felt about eating the meat presented.

\subsubsection{State dissociation}

The three items used in the previous study were adapted to the present context to measure dissociation as reaction to the advertisement (e.g., "The first thing I thought about when I saw the meat displayed above was a living being"; $\alpha=0.75$ ). The items were reversed scored so that higher scores meant more state dissociation.

\subsection{Results}

Correlations between the main variables are presented in Table 2. As expected, participants showed more empathy, $t(185)=-3.51, p=0.001$, and less state dissociation, $t(185)=6.67$, $p<0.001$, when the lamb was presented in the advertisement (see Fig. 6). Moreover, they were less willing to eat meat when the lamb was presented than when it was not presented, $t(185)=3.33$, $p=0.001$ (see Fig. 4). No effects were observed on attribution of mind (sensation: $p=0.978$; intellect: $p=0.788$ ), which disqualified the measure as mediator in the path model presented later on. While gender did not moderate the experimental effects (0.121 $<p<0.441)$, women showed more trait dissociation $(M=4.79, S D=1.72)$ but less state dissociation $(M=3.52$, $S D=1.64)$ than men did - trait dissociation: $M=4.10, S D=1.67$, $t(185)=-2.74, p=0.007$; state dissociation: $M=4.15, S D=1.44$, $t(185)=2.73, p=0.007$.

We set out to replicate the mediation model from Study 2a. Again, state dissociation fully mediated the effect of the experimental manipulation on empathy, and together with empathy mediated the experimental effect on willingness to eat meat (see Fig. 7). Bootstrapping indicated that both the indirect effects on empathy $(\beta=0.32, S E=0.05,95 \% \mathrm{CI}[0.23,0.42], p<0.001)$ and on meat eating were significant $(\beta=-0.25, S E=0.06,95 \% \mathrm{CI}[-0.36$, -0.12 ], $p<0.001)$. A small and positive direct effect of state dissociation on willingness to eat meat remained significant (see Fig. 7).

Last, we ran moderated regression models to test whether the experimental effects on state dissociation, empathy and meat eating would be especially pronounced among participants who scored high on trait dissociation. The interactions between the

Table 2

Means, standard deviations and correlations between main study variables in study 3.

\begin{tabular}{|c|c|c|c|c|c|c|c|}
\hline Variable & $M$ & $S D$ & 2. & 3. & 4. & 5. & 6. \\
\hline $\begin{array}{ll}1 & \text { Trait } \\
& \text { dissociation }\end{array}$ & 4.49 & 1.73 & $0.36^{* * *}$ & 0.05 & 0.07 & $-0.17^{*}$ & $-0.24^{* *}$ \\
\hline 2 Empathy & 4.11 & 1.89 & & $0.25^{* *}$ & $0.30^{* * *}$ & $-0.69 * * *$ & $-0.84 * * *$ \\
\hline $\begin{array}{l}3 \text { Capacity } \\
\text { sensation }\end{array}$ & 5.75 & 1.34 & & & $0.54^{* * *}$ & $-0.21^{* *}$ & $-0.16^{*}$ \\
\hline $\begin{array}{l}4 \text { Capacity } \\
\text { intellect }\end{array}$ & 4.00 & 1.52 & & & & $-0.22 * *$ & $-0.23^{* *}$ \\
\hline $\begin{array}{l}5 \text { State } \\
\text { dissociation }\end{array}$ & 3.79 & 1.58 & & & & & $0.65^{* * *}$ \\
\hline $\begin{array}{l}6 \text { Willingness } \\
\text { to eat meat }\end{array}$ & 52.36 & 35.39 & & & & & \\
\hline
\end{tabular}

Note. ${ }^{*} p<0.05,{ }^{* *} p<0.01,{ }^{* * *} p<0.001$

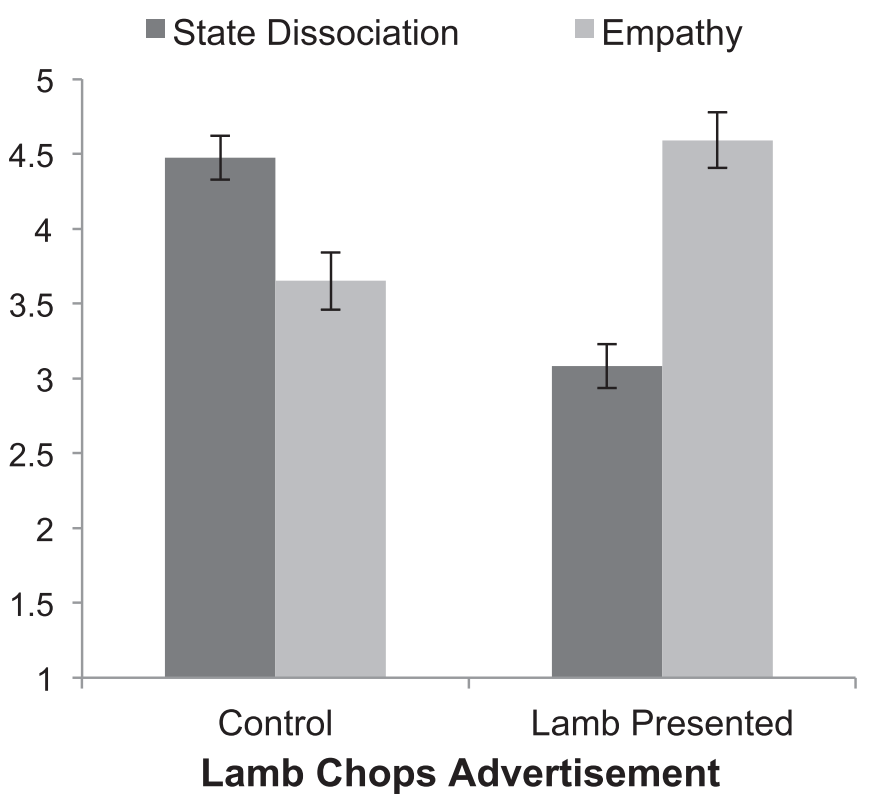

Fig. 6. In Study 3, participants showed less state dissociation and more empathy when a lamb was displayed in the lamb chops advertisement. \pm 1 SE are displayed.

experimental manipulation and trait dissociation were significant for all variables-empathy: $\beta=0.15, p=0.026 ; F(3,183)=15.50$, $p<0.001$; state dissociation: $\beta=-0.18, p=0.006 ; F(3,183)=19.87$, $p<0.001$; willingness to eat meat: $\beta=-0.14, p=0.053 ; F(3$, $183)=8.90, p<0.001$. Simple slopes showed that when the lamb was presented, empathy increased only among participants who scored medium and, especially, among those who scored high on trait dissociation (see Fig. 8). Similarly, especially among those who scored high on trait dissociation did the experimental manipulation produce a substantial drop in state dissociation. Last, willingness to eat meat dropped only among those who had medium or high levels of trait dissociation.

\subsection{Preliminary discussion}

The results demonstrated how portrayals of animals in meat advertisements increase empathy as a consequence of reduced dissociation. When a living lamb was presented alongside lamb chops in an advertisement, participants showed more empathy towards the animal that had to die to produce the chops, and this relation was fully due to a decrease in dissociation. Moreover, participants were less willing to eat the lamb chops when the animal was presented, and this was precisely due to this increase in empathy.

Although empathy substantially mediated the effects as secondorder mediator, a weak positive effect of dissociation on willingness to eat meat remained significant. Hence, alternative mediators may be at play. Lorenz (1970) argued that animals, which have facial and body features that make them look "cute" and resemble human babies, release a mechanism in humans to protect and nurture them. Admittedly, the lamb in our advertisement may look cute and innocent to participants. Hence, while disgust is an unlikely alternative mediator here, some type of "cuteness" reaction may have also mediated the effects.

After the first three studies demonstrated how meat processing and presentation affect empathy and disgust as a process of dissociation, we aim to demonstrate similar processes at the linguistic level in the next two studies. 


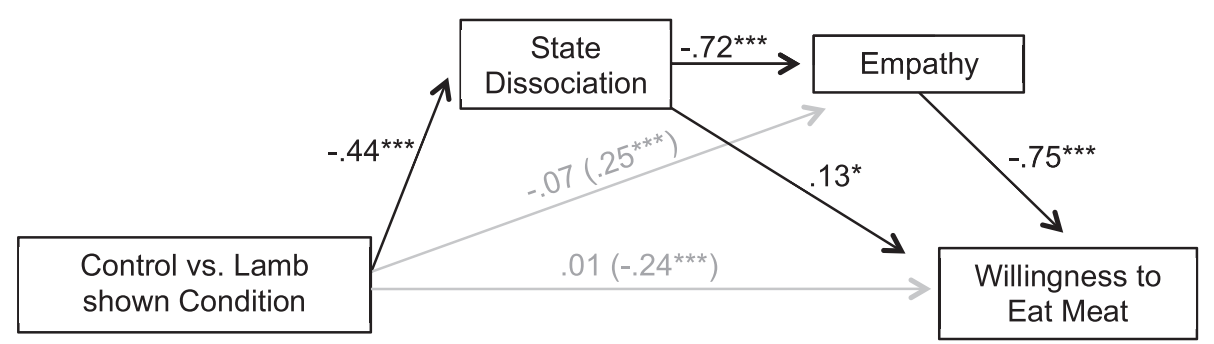

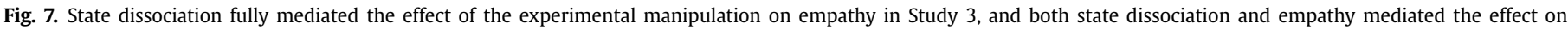

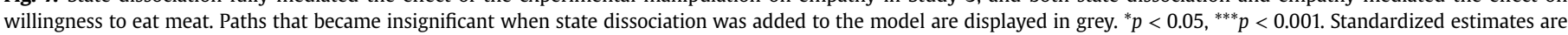
displayed.

\section{Study 4}

Every day, hundreds of thousands animals are slaughtered to produce meat products. However, the ways in which this process is referred to varies. For instance, while animal rights activists may describe it as "killing", the food industry may refer to it as "harvesting" (Stibbe, 2001), a term that according to the Oxford dictionary in fact can describe "a quantity of animals caught or killed for human use".

The way we talk about certain phenomena (i.e., how they are framed) influences our evaluations and choices (Keren, 2011; Lakoff, 2004). People pay more for a burger described as $75 \%$ lean than one described as 25\% fat (Levin \& Gaeth, 1988), and are more willing to choose the more expensive airline ticket including a carbon fee when the fee is framed positively (as an offset) compared to when it is framed negatively (as a tax; Hardisty, Johnson, \& Weber, 2010). Along these lines, we set out to test whether framing the food industry's large-scale killing of animals using the euphemism "harvesting" as compared to "killing" or "slaughtering" would increase dissociation, leading to less empathy.

\subsection{Method}

\subsubsection{Participants}

A total of 292 US Americans were recruited through Amazon $\operatorname{MTurk}\left(M_{\text {age }}=35.54, S D_{\text {age }}=12.38\right.$; women: $\left.52.5 \%\right)$. Of these, $88.0 \%$

\section{Trait Dissociation}
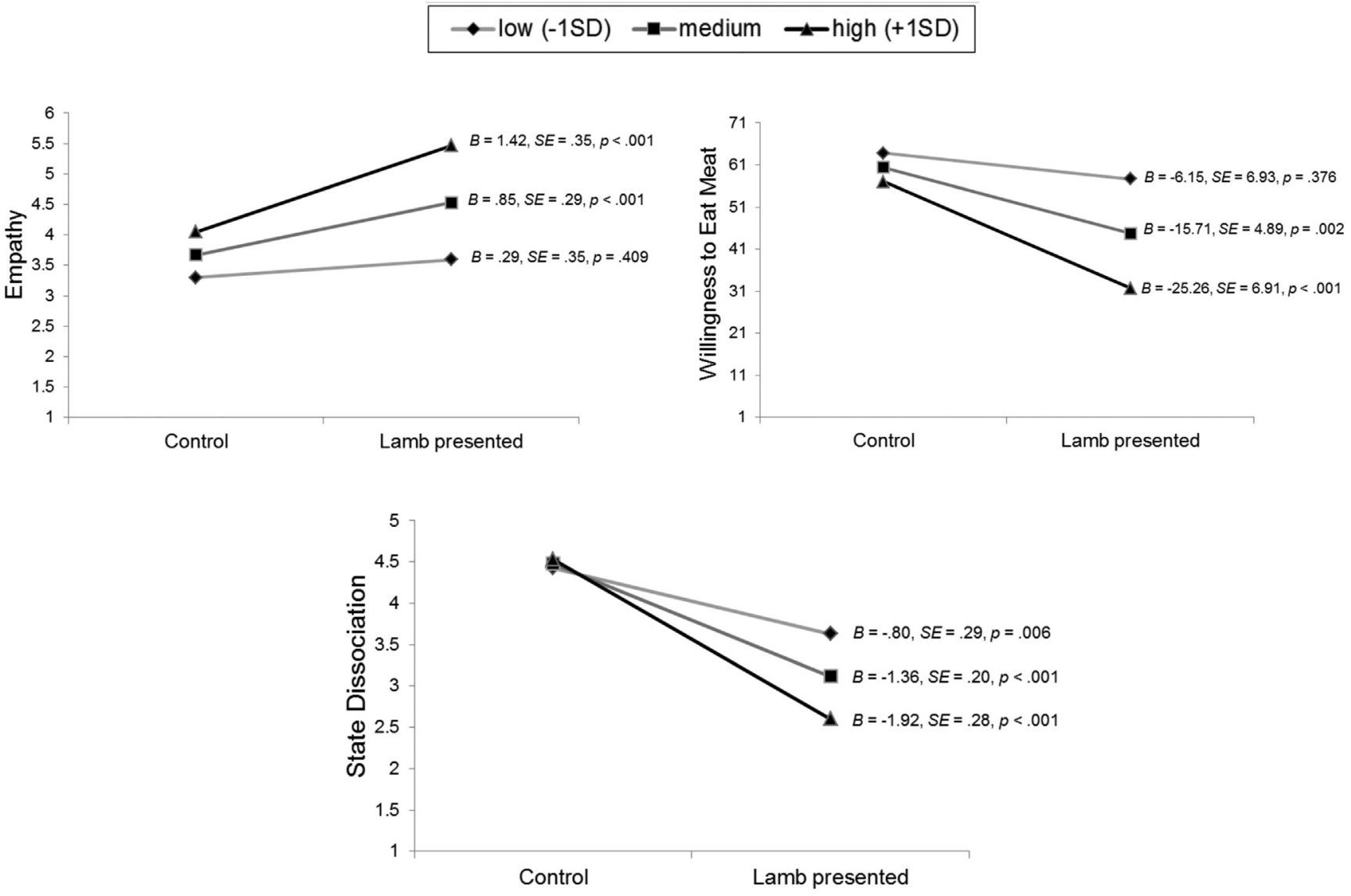

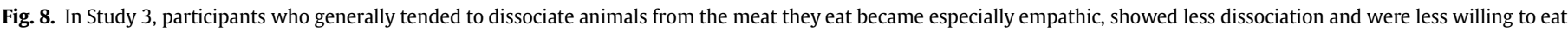
the lamb meat when a living lamb was presented in the meat advertisement. 
reported to be omnivores, $6.2 \%$ reported to be pescetarians, $4.1 \%$ to be vegetarians and $1.7 \%$ to be vegan. On average, participants reported to eat meat 4.75 times per week $(S D=2.17)$.

\subsubsection{Procedure}

Participants were randomly assigned to one of three conditions. In each condition, participants read the same text with the difference that the verb was varied between conditions:

"30.2 million cows were [experimental condition: harvested/ slaughtered/killed] for food production in the US last year, according to USDA statistics."

Hence, for one third of the participants, the verb in the sentence constituted either harvested, slaughtered or killed. The text was presented on top throughout the survey, except on the demographics section and the informed consent. Participants completed the following measures:

\subsubsection{Empathy}

Respondents rated their empathy towards the cows on the measure from the previous studies adapted to the present context ( $\alpha=0.96$ ). Importantly, the verb in each of these items was matched to the respective condition (i.e., harvest condition: "I feel sorry for the animals that were harvested", slaughter condition: "I feel sorry for the animals that were slaughtered", kill condition: "I feel sorry for the animals that were killed").

\subsubsection{State dissociation}

We asked participants to rate the degree to which the word in the respective condition reminded them of the fact that the dead animals once had been living beings: "How much does the word '[harvested/slaughtered/killed]' remind you of the fact that animals lost their lives?" and "How much does the word "[harvested/ slaughtered/killed]' remind you of the fact that the animals were living beings?" both rated from 0 (not at all) to 100 (extremely). Hence, given that the manipulation in this study was linguistic and dealt with a large amount of animals rather than a specific piece of meat as in the previous studies, state dissociation here reflects the mental separation between the killed animals and the living animals. These highly correlated items $(r=0.87, p<0.001)$ were reversed before a mean dissociation score was created.

\subsection{Results}

As expected, participants differed in the degree to which the words reminded them of the fact that the animals had been living beings, $F(2,290)=17.39, p<0.001, \eta_{\mathrm{p}}^{2}=0.11$. LSD post-hoc tests showed that those in the harvested condition showed more state dissociation than those in the kill and slaughter conditions (see Fig. 9). Gender did not moderate the effects $(0.105<p s<0.138)$. As the killed and slaughtered conditions did not differ from each other ( $p=0.769$ ), both were merged and compared to the harvest condition in consecutive analyses similar to analytic procedures in previous research (Kimel, Huesmann, Kunst, \& Halperin, 2016; Kunst, Thomsen, Sam, \& Berry, 2015).

Although no direct effect of the experimental manipulation on the empathy ratings was observed, $F(2,290)=0.16, p=0.853$, mediation analyses showed that it had an indirect effect on empathy that was mediated by state dissociation. Specifically, path analysis showed that the experimental dummy variable (coded as: $0=$ merged 'killed' and 'slaughtered' condition, 1 = 'harvested' condition) led to more state dissociation, which, in turn, was related to less empathy $(\beta=-0.53, p<0.001)$. Finally, bootstrapping showed that the resulting indirect effect was significant, $\beta=-0.18, \mathrm{SE}=0.03,95 \% \mathrm{CI}[-0.25,-0.12], p<0.001$.

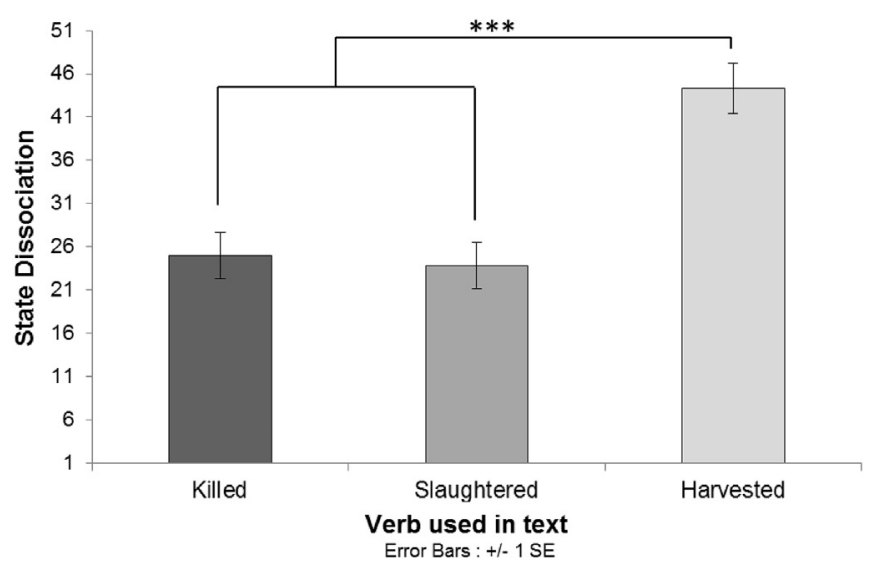

Fig. 9. In Study 4, participants showed more dissociation when the term 'harvested' was used than when 'killed' and 'slaughtered' were used. ${ }^{* * *} p<0.001 . \pm 1$ SE are displayed.

\subsection{Preliminary discussion}

As expected, the term "harvested" increased dissociation as compared to "killed" and "slaughtered". While no direct effects on empathy were observed, this difference in dissociation indirectly led to less empathy towards the animals that were described in the text. While euphemisms such as "harvesting" may affect one's stance towards meat, people are less commonly exposed to them in public discourse or consumer choice situations, when food decisions are actually made. In the next study, we therefore tested whether the terms "beef" and "pork" that are commonly used to refer to cow and pig meat in consumer situations would serve the function of dissociation, and consequently increase willingness to eat meat, as has been suggested (Adams, 2004; Singer, 1995).

\section{Study 5}

The previous study showed that euphemisms describing the killing of animals by the meat industry elicited processes of dissociation with downstream effects on empathy. This last study tests whether terms commonly used to describe the meat endproduct have similar effects. It has been suggested that referring to meat with terms such as beef and pork "disguises the fact that the body parts we purchase and consume are the objectified remains of former subjects" (Glenn, 2004, p. 69). Consequently, these terms should bolster the process of dissociation and thereby lead to less empathy and disgust, and to more willingness to eat the meat. To test this, we present participants with one of two matched restaurant food menus. In one condition, the dishes in the menu are described with the terms "beef" and "pork", that is, the terms that are commonly used in restaurants. In the other condition, which we expect to interrupt the dissociation process, these terms are replaced by "cow" and "pig".

As in Study 3, we include a measure of individual tendencies to dissociate animals from meat and expect a particularly pronounced effect for participants with high trait dissociation. We predict this interaction effect in the scenario of the present study because the words "cow" and "pig" are usually used in contexts describing living animals, not in contexts describing potential food to be consumed. Such animal terms should therefore complicate dissociation especially for people who usually have to exert themselves to not think about the animal origins of meat to be able to consume it, and hence should reduce willingness to eat the meat particularly within this group. 


\subsection{Method}

\subsubsection{Participants}

A total of 190 participants were recruited through Amazon MTurk $\left(M_{\text {age }}=33.59, S D_{\text {age }}=10.18 ; 52.1 \%\right.$ women $)$. Of these, $93.7 \%$ reported to be omnivores, $3.7 \%$ to be pescetarians, $2.7 \%$ to be vegetarians and $0.5 \%$ to be vegans. On average, participants reported to eat pork 1.64 days per week $(S D=1.42)$ and beef 2.60 days per week $(S D=1.64)$.

\subsubsection{Procedure}

Participants first completed the trait dissociation measure (i.e., the moderator; $\alpha=0.93$ ) and the filler tasks from Study 3. Next, they were told that they were about to see a food menu and were asked to read it as if they were customers in a restaurant. Here, participants were randomly assigned to one of two conditions: In the beef/pork condition, the menu that was presented to participants used the common words "beef" and "pork" to describe the meat dishes. In the cow/pig condition, these were replaced by the respective animal terms. The menus were matched in content, design and size (see Table 1) and presented on top while participants completed the following measures:

\subsubsection{Empathy}

The measure from the previous studies was adapted and used to measure the empathy that reading the menu evoked (e.g., "When I see the menu, I feel sorry for the animals that were slaughtered"; $\alpha=0.96)$.

\subsubsection{Disgust}

The measure from Study $2 \mathrm{~b}$ was used to assess the degree to which the menu elicited feelings of disgust $(\alpha=0.98)$.

\subsubsection{Willingness to eat meat}

Using the same measure as in Study 2 and 3, we asked participants how positive they felt about eating the meat dishes presented in the menu.

\subsubsection{Preference for vegetarian alternative}

As in Study 2b, we also asked participants how likely it would be that they would chose a vegetarian alternative from the menu, given that it was offered.

\subsubsection{State dissociation}

The state dissociation measure from the first three studies was adapted to the present context to assess participants' degree of dissociation as reaction to the menu $(\alpha=0.74)$.

Table 3

Means, standard deviations and correlations between main study variables in study 5 .

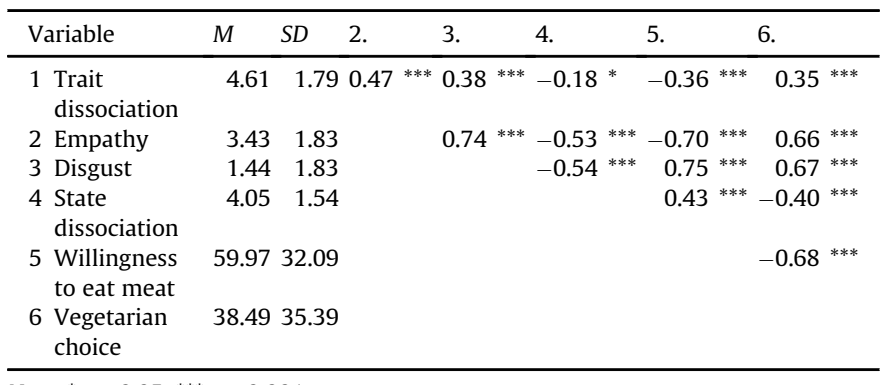

Note. ${ }^{*} p<0.05,{ }^{* * *} p<0.001$

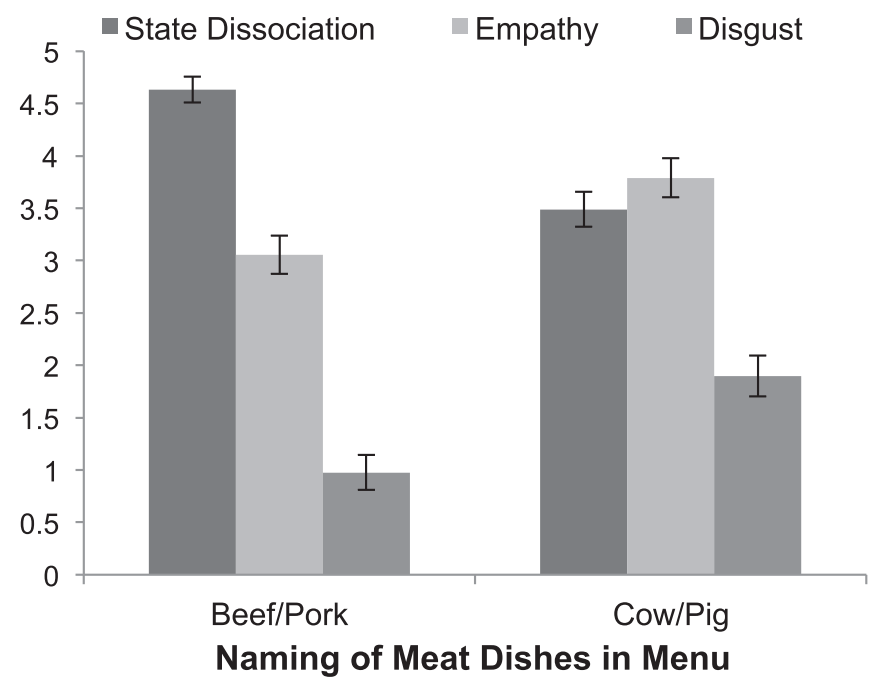

Fig. 10. Replacing "beef" with "cow" and "pork" with "pig" in a restaurant menu decreased state dissociation, and increased empathy and disgust in Study 5. \pm 1 SE are displayed.

\subsection{Results}

Correlations between the main variables are presented in Table 3. State dissociation decreased, $t(188)=5.49, p<0.001$, while empathy, $t(188)=-2.80, p=0.005$, and disgust, $t(188)=-3.59$, $p<0.001$, increased when "beef/pork" were replaced with "cow/ pig" in the restaurant menu (see Fig. 10). Also, willingness to eat the dishes displayed in the menu dropped once the animal words were used, $t(188)=3.59, p<0.001$, see Fig. 4 . Last, participants were marginally significantly more likely to consider a vegetarian alternative when the animal labels were used $(M=43.12, S E=3.84)$ than when "beef" and "pork" were used $(M=33.78, S E=3.49)$, $t(188)=-1.80, p=0.074$. None of the experimental effects were moderated by participants' gender $(0.140<p s<0.801)$. However, as in Study 3, women $(M=5.13, S D=1.62)$ showed more trait dissociation than men $\operatorname{did}(M=4.01, S D=1.79), t(187)=-4.52$, $p<0.001$, but this time no gender difference was observed for state dissociation $(p=0.798)$.

Having established these effects, we set out to replicate the path model from Study $2 \mathrm{~b}$ with this study's experimental manipulation ( 0 = "beef/pork", $1=$ "cow/pig") as predictor. In contrast to Study $2 \mathrm{~b}$, where we expected the presentation of the animal's head to lead to more state dissociation, we expected the present experimental manipulation to interrupt, and hence reduce, the process of dissociation. The model achieved very close fit to the data $\chi^{2}(d f=5$, $N=190)=4.62, p=0.463$, RMSEA $<0.001, \mathrm{CFI}=1.00$. As expected, the experimental manipulation led to less state dissociation, which, in turn, led to less empathy and less disgust (see Fig. 11). Bootstrapping showed that the indirect and positive effects of the experimental manipulation on empathy $(\beta=0.20, S E=0.04,95 \% \mathrm{CI}$ $[0.12,0.29], p<0.001)$ and disgust $(\beta=0.19, S E=0.04,95 \% \mathrm{CI}[0.12$, $0.29], p<0.001$ ) were significant and did not differ in strength $(\Delta \beta=0.00, S E=0.02,95 \% \mathrm{CI}[-0.03,0.04])$. No direct effect was observed of the experimental manipulation on disgust.

As empathy and disgust both predicted less willingness to eat the meat dishes in the menu and a higher likelihood to choose a vegetarian alternative, the experimental manipulation had an indirect and inverse effect on willingness to eat the meat dishes $(\beta=-0.19, S E=0.04,95 \% \mathrm{CI}[-0.28,-0.12], p<0.001)$ and an indirect positive effect on likelihood to eat vegetarian ( $\beta=0.17$, $S E=0.04,95 \% \mathrm{CI}[0.11,0.25], p<0.001)$. The strength of the indirect 


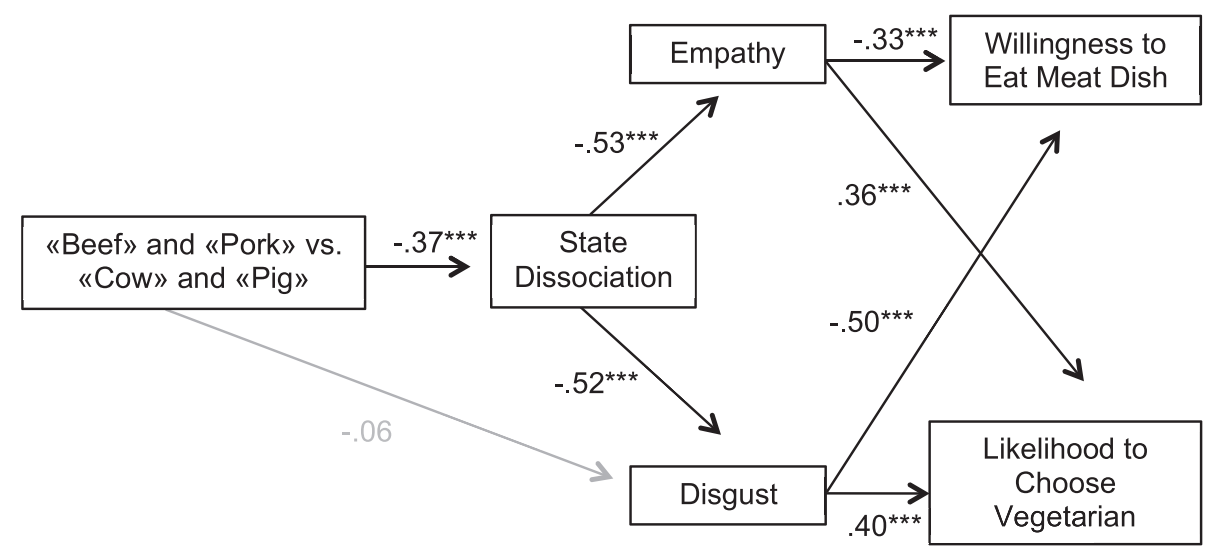

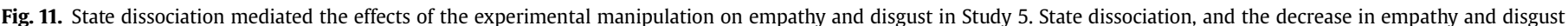

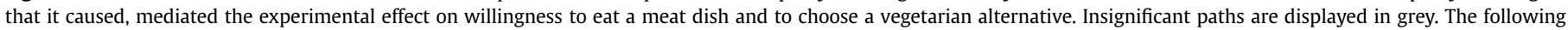

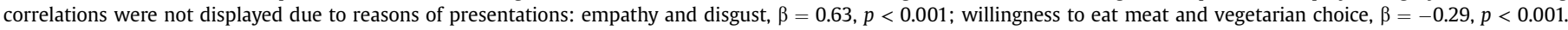
${ }^{* * *} p<0.001$. Standardized estimates are displayed.

effects on the outcome variables that were mediated by empathy did not differ significantly from those mediated by disgust (willingness to eat meat dish as dependent variable: $\Delta \beta=0.03$, $S E=0.03,95 \% \mathrm{CI}[-0.03,0.11]$; likelihood to choose vegetarian as dependent variable: $\Delta \beta=-0.01, S E=0.03,95 \% \mathrm{CI}[-0.07,0.06])$.

Last, we tested whether the experimental effects would be moderated by trait dissociation as in Study 3. Here, the interaction terms between the experimental manipulation and trait dissociation were significant for disgust $(\beta=0.14, p=0.035 ; F(3$, $186)=15.58, p<0.001)$ and marginally significant for state dissociation $(\beta=-0.11, p=0.089 ; F(3,186)=12.29, p<0.001)$, but insignificant for empathy $(\beta=0.10, p=0.117 ; F(3,186)=21.96$, $p<0.001)$, willingness to eat a meat $\operatorname{dish}(\beta=-0.09, p=0.160 ; F(3$, $186)=13.12, p<0.001)$ and likelihood of choosing a vegetarian alternative $(\beta=0.09, p=0.166 ; F(3,186)=9.72, p<0.001)$. Nevertheless, simple slopes analyses showed a similar pattern as in Study 3. The experimental manipulation increased empathy and disgust and decreased willingness to eat meat only among those with moderate and high trait dissociation, and had particularly pronounced positive effects on state dissociation within this group (see Fig. 12).

\section{General discussion}

Rachels (2004) argues that even most meat eaters will agree with the dominant argument for vegetarianism; that 1 ) it is wrong to cause unnecessary pain and suffering; 2) eating meat causes unnecessary pain and suffering; 3 ) so eating meat is wrong. Hence, meat eaters have to reconcile their diet with the fact that they dislike causing pain to animals. However, the sterile supermarket presentation of meat makes the second argument extremely easy to ignore, and the conclusion is therefore never forced upon meat consumers (Hopkins \& Dacey, 2008). In six experimental studies, we empirically demonstrated that meat practices in the modern world indeed facilitate divorcing meat products from their animal origins, thereby reducing empathy and disgust, which ultimately bolsters meat consumption.

The first study showed that the more processed meat is, the easier it is to dissociate it from an animal being, and that this produces a drop in empathy for the animal that was killed. Most people buy highly processed meat in the supermarket on a daily basis, and are vastly uninvolved in all the major processing steps that gradually remove the animal resemblance from the carcass (Lerner \& Kalof, 1999). As the results of the first study suggest, buying meat at this late stage of processing may make it particularly easy to mentally disengage it from its animal origin.

Because the baseline picture in this first study already was relatively processed (e.g., the hen's head had been removed), it was important to follow up on these effects using a relatively unprocessed animal as baseline. Moreover, we were interested in seeing whether the processes observed in the first study would extend to eating intentions. In the second study, we therefore showed that simply removing the head from a pork roast produced a substantial decrease in empathy, which again was fully explained by an increase in dissociation. Importantly, results showed that removal of the animal's head made participants also feel more willing to eat its meat and again this was due to an increase in dissociation and the drop in empathy it had caused. Attribution of mind was unaffected by the experimental manipulation although it was the head that was removed and, hence, seemed to play little of a role here.

Following up on these results, we replicated our findings in a next study, this time showing that the positive effects that beheading of a pork roast had on willingness to eat the meat (and the negative effects it had on choosing a vegetarian alternative dish) were equally mediated by a decrease in empathy and feelings of disgust. For most of the meat that is available in Western supermarkets, the head has been removed and is not visible to the consumer. Based on the results, one may speculate that this is done not only because head parts are less common in Western cuisine, but also because presenting it may elicit both disgust and empathy, which may substantially reduce meat buying and consumption. However, it should be noted that the presence of a head may have been a particularly strong cue in the Western context of our study because Western consumers are no longer familiar with seeing the head of the animal they will eat. Hence, future studies may test whether our findings can be replicated in cultures where unprocessed carcasses are a common sight.

Study 3 demonstrated that seeing a living animal in a food advertisement disrupts dissociation. When we displayed a living animal in a meat advertisement, this greatly reduced dissociation, increasing empathy and decreasing willingness to eat the meat. Thus, meat advertisements that contain visual cues of animals may from a business perspective be less effective because they interrupt the dissociation process that otherwise upholds meat consumption. However, not all participants were equally affected by seeing the living animal in the ad. Although the dissociation process was somewhat interrupted among all participants, this was particularly the case for those who generally spend efforts dissociating the meat 


\section{Trait Dissociation}
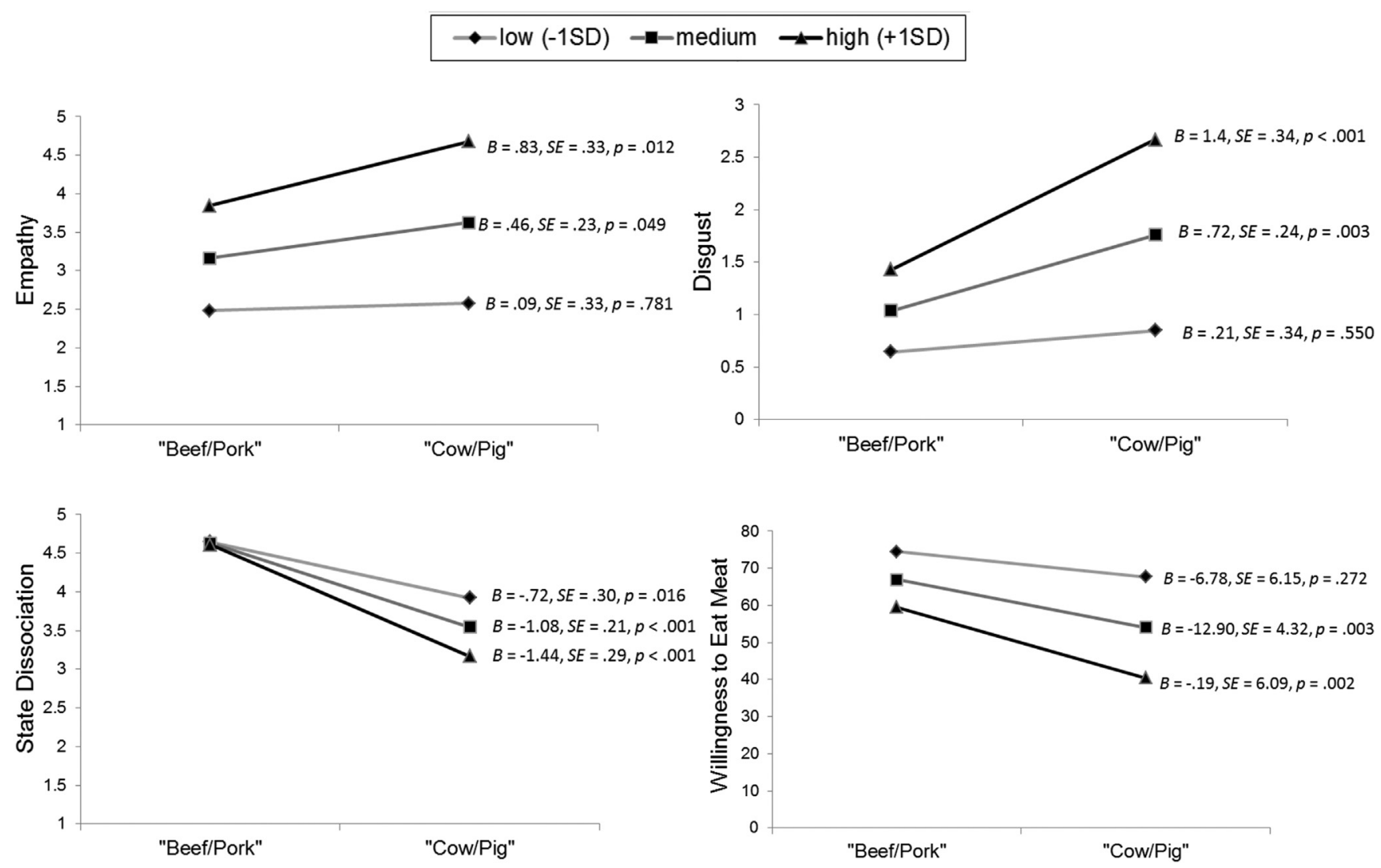

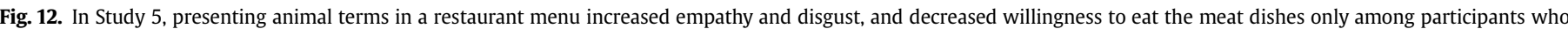

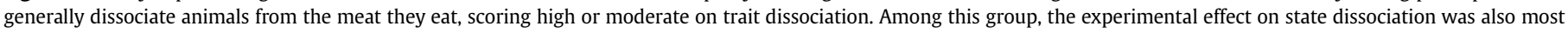
pronounced.

they eat from its animal origin. Also, only among the latter group did seeing the living animal produce an increase in empathy and more negativity towards eating the meat. Thus, although our results suggest that presenting animals in meat advertisement may change the consumer attitudes and behavior of many people, it may have no effect among those for whom dissociation generally plays little of a role. In regard of the framework adopted in this third study, it is also important to note that animal well-fare concerns have started to play a considerable role for people's meat consumption (Harper \& Henson, 2001), and cues indicating animal friendly production may influence consumer behavior (Harper \& Makatouni, 2002; Toma, Stott, Revoredo-Giha, \& Kupiec-Teahan, 2012). For instance, displaying an animal grazing in a farming landscape may have the opposite effects than simply showing the animal as in our study because it may signal animal welfare and thereby relieve consumers' bad consciousness to some degree.

We also tested how minor linguistic manifestations may bolster processes of dissociation. In the fourth study, framing the annual mass slaughter of 30.2 million cows by the U.S. food industry through the euphemism "harvesting" (as opposed to "killing" or "slaughtering") produced an increase in dissociation. Although the framing effects seemed to be too weak to directly affect empathy for the animals that had died, they did so indirectly, mediated by dissociation. When we, however, replaced the words "beef" and "pork" that people are frequently exposed to with "cow" and "pig" in a restaurant menu, this substantially reduced willingness to eat meat, and participants even tended to be more likely to consider a vegetarian alternative. In this last study, disgust again emerged as equally powerful mediator as empathy. That is, reading "cow" and "pig" in the menu evoked more empathy for the slaughtered animals but also more disgust, which both reduced willingness to eat the dishes while increasing the likelihood of choosing a vegetarian alternative. Disgust is central in determining people's attitudes towards eating animal products (Rozin \& Fallon, 1980, 1987), and as our study suggests, dissociation may maintain meat consumption as it suppresses empathy and disgust equally. As in Study 3, the experimental effects were moderated by the degree to which participants generally used the strategy of dissociation in their daily lives. Although some of the interactions fell below significance, simple slopes showed that effects were especially pronounced for those who generally are prone to dissociation. Interestingly, the experimental manipulation elicited feelings of disgust particularly among those with high trait dissociation. Hence, as one limitation of the present research involves that we only included disgust in contexts where we found it to be especially relevant, this finding further underlines the importance of future research to consider disgust as additional mediator.

\subsection{Dissociation or denial of mind? Two pathways to meat consumption}

Although earlier work has suggested that denial of mind is a major strategy to solve the meat paradox and has suggested that it particularly comes online when people are reminded of the animalmeat link (Bastian, Loughnan, et al., 2012), the present studies find dissociation to be a more powerful strategy in such scenarios. In both 
studies where denial of mind was tested as alternative mediator, the measure remained unaffected by the experimental manipulations. Specifically, participants did not rate the animal's mental capacities differently when the head was removed from a pork roast (Study 2a) or when the picture of an animal was shown in a restaurant menu (Study 3). However, the experimental manipulations led to large differences in state dissociation, which by affecting empathy and disgust, in turn, explained participants' willingness to eat meat.

According to Bastian, Costello, et al. (2012) and Bastian, Loughnan, et al. (2012), the meat paradox arises when people eat meat although they dislike causing harm to animals, such that their behavior conflicts with their concern for animal welfare. They further state that "meat eaters go to great lengths to overcome these inconsistencies between their beliefs and behaviors" (Bastian, Loughnan, et al., 2012, p. 247). However, we argue that thanks to modern meat industry and the concealing of animal reminders in most meat products, consumers will often not need to go to such great lengths. Thus, by neglecting the link between meat and animals overall, the inconsistency between eating animals while not wanting to hurt them becomes less evident, and individuals will not experience bothersome dissonance, often rendering denial of mind unnecessary. This notion is further supported by the results of our moderation analyses. In the control conditions, even people who scored high on trait dissociation (generally spending considerable efforts dissociating meat from its animal origins in their daily lives) differed little in state dissociation from those scoring lower on trait dissociation. Crucially, in these control conditions, meat was presented in the way that is typical in many western cultures. This again suggests that the way meat and meat products are presented to customers substantially facilitates the dissociation process, making alternative strategies virtually unnecessary even for those who may struggle with the meat paradox the most.

This is not to say that denial of mind plays no role for meat consumption. Possibly, dissociation and denial of mind work in concert with each other and are used in different contexts. We propose that dissociation and its subsequent suppression of empathy and disgust represents a more immediate and affective pathway sustaining meat consumption. This pathway may be dominant especially in consumer choice situations and when confronted directly with meat stimuli. Denial of mind, on the other hand may represent more of a cognitive-evaluative pathway. Downgrading of mental capacities of the animal may primarily come into play when active legitimization of one's own behavior becomes necessary, such as after people have made the choice to, or have already, consumed meat (Bastian, Loughnan, et al., 2012; Loughnan et al., 2010). Given that people are most likely to deny the mind of humans and animals when they feel responsible for the harm caused to them (Bandura, 1999; Bastian, Loughnan, et al., 2012; Castano \& Giner-Sorolla, 2006), one may also expect denial of mind to be a strategy that is used when people are explicitly told that animals they eat or ate were treated badly, or to be a strategy that is used by people actively involved in the killing of animals.

\subsection{Strengths, limitations and future research}

Before concluding, some strength and limitations of the present studies should be noted. The fact that the same pattern of results was observed across different animal types and different contexts suggests that it represents a general process that is not limited to a specific type of animal or context. However, it should be noted that effects on empathy were weakest in Study 1, where the experimental condition was a chicken at different stages of processing. This comparably weak effect could be due to the fact that this was the only study that used a bird rather than a mammal as stimulus. Because humans feel higher empathy for mammals than birds
(Kubberød et al., 2002; Westbury \& Neumann, 2008), future studies could directly test how animal type (i.e., mammals versus nonmammals) moderates the roles of dissociation, empathy and disgust.

Trait dissociation was tested as a moderator only in Study 3 and 5. Ideally, this moderator could have been measured also in the two first studies, but in these preliminary studies the aim was to establish the general effects before exploring the complexity of these effects by testing for moderation later on. Moreover, we considered individual tendencies to dissociate meat from animals as relevant only in studies that actually involved presentation of meat products. Trait dissociation was therefore not included in Study 4, because the experimental manipulation here was a linguistic frame of the slaughtering process, not different presentations of meat products.

To avoid deception, participants did not receive any cover story prior to participation. However, they were not informed about the specific aims of the study or its experimental nature so that demand characteristics should have been minimal. Still, demand characteristics may have affected responses to some extent in Study 3 , in which a picture of a lamb was displayed in only one of the food menus, but are less likely in the remaining studies because animal stimuli were present in all conditions. Related to this, in all studies we used explicit self-report measures. Future studies may profitably address whether our paradigm can be replicated with implicit or indirect types of measures, which also may reduce potential demand characteristics. For instance, implicit association tests may be used to measure spontaneous dissociation tendencies based on reaction times. Moreover, skin conductance and facial expressions may be used as physiological measure of affective reactions such as disgust and empathy.

Results were obtained using real-world stimuli, such as food menus and descriptions, with high resemblance to what people regularly are confronted with in their daily lives. We therefore argue that our studies have high ecological validity. Nevertheless, because manipulations simulated consumer choice situation, we only measured behavioral intentions rather than real behavior. Köster (2009) emphasizes the need for food choice research to increase ecological validity by taking into account the dynamic and complex interactions between food products, individual consumers and choice environment. Future studies should therefore test the effects of dissociation using field experiments (i.e., in real food choice situations such as restaurants or food-stores), and include individual, contextual or product-related factors that may influence the effects.

Last, regular contact with farm animals can lead to more relaxed attitudes to animal production and less disgust reactions in relation to meat and meat-eating (Kubberød et al., 2002). Future studies could investigate the degree to which personal differences such as exposure to farm animals interact with trait and state dissociation.

\section{Conclusion}

Using a variation of scenarios with real-world stimuli and simulated consumer-choice situations, this line of research experimentally demonstrated what many philosophers and animal rights advocates have claimed for long times (e.g., Adams, 2004; Dunayer, 2001; Singer, 1995; Stibbe, 2001): Culturally entrenched processes of dissociation found in the way we produce, prepare and talk about meat and animals sustain people's willingness to eat meat as they make it easy to ignore the meat-animal link. Such dissociation reduces empathy and disgust that would otherwise reduce meat consumption. 


\section{Acknowledgements}

We thank the editor Dr. Suzanne Higgs, the first reviewer, and the second reviewer Dr. Hank Rothgerber for valuable comments that helped improving this paper considerably.

\section{References}

Adams, C. (2004). The sexual politics of meat. NY, US-NY: Continuum.

Bandura, A. (1999). Moral disengagement in the perpetration of inhumanities. Personality and Social Psychology Review, 3(3), 193-209. http://dx.doi.org/ 10.1207/s15327957pspr0303_3.

Bastian, B. (2011). The meat paradox: How we can love some animals and eat others The conversation.

Bastian, B., Costello, K., Loughnan, S., \& Hodson, G. (2012). When closing the human-animal divide expands moral concern: The importance of framing. Social Psychological and Personality Science, 3(4), 421-429. http://dx.doi.org $10.1177 / 1948550611425106$

Bastian, B., Loughnan, S., Haslam, N., \& Radke, H. R. M. (2012). Don't mind meat? the denial of mind to animals used for human consumption. Personality and Social Psychology Bulletin, 38(2), 247-256. http://dx.doi.org/10.1177/ 0146167211424291.

Beardsworth, A. \& Keil, T. (1992). The vegetarian option: Varieties, conversions, motives and careers. The Sociological Review, 40(2), 253-293.

Belasco, W. (2008). Food: The key concept. Oxford, United Kingdom: Berg.

Bentler, P. M., \& Chou, C.-P. (1987). Practical issues in structural modeling. Sociological Methods \& Research, 16(1), 78-117. http://dx.doi.org/10.1177/ 0049124187016001004

Bohm, I., Lindblom, C., Åbacka, G., Bengs, C., \& Hörnell, A. (2015). "He just has to like ham" - The centrality of meat in home and consumer studies. Appetite, 95, 101-112. http://dx.doi.org/10.1016/j.appet.2015.06.015.

Brown, L. M., Bradley, M. M., \& Lang, P. J. (2006). Affective reactions to pictures of ingroup and outgroup members. Biological Psychology, 71(3), 303-311. http:// dx.doi.org/10.1016/j.biopsycho.2005.06.003.

Castano, E., \& Giner-Sorolla, R. (2006). Not quite human: Infrahumanization in response to collective responsibility for intergroup killing. Journal of Personality and Social Psychology, 90(5), 804-818. http://dx.doi.org/10.1037/00223514.90.5.804.

Cerjak, M., Karolyi, D., \& Mesić, Ž. (2011). Consumers' attitudes towards farm animal welfare and their influence on meat consumption. Agriculturae Conspectus Scientificus (ACS), 76(4), 283-286.

Cole, J. (2001). Empathy needs a face. Journal of Consciousness Studies, 8(5-7), $51-68$.

Davis, M. H. (1980). A multidimensional approach to individual differences in empathy. JSAS Catalog of Selected Documents in Psychology, 10(85).

De Waal, F. (2009). The age of empathy. Nature's lessons for a kinder society. London, United Kingdom: Souvenir Press.

Dunayer, J. (2001). Animal equality: Language and liberation. Derwood, US-MD: Ryce.

Filippi, M., Riccitelli, G., Falini, A., Di Salle, F., Vuilleumier, P., Comi, G., et al. (2010). The brain functional networks associated to human and animal suffering differ among omnivores, vegetarians and vegans. PLoS One, 5(5), 1-9. http:/ dx.doi.org/10.1371/journal.pone.0010847.

Foer, J. S. (2010). Eating animals. New York, US-NY: Back Bay Books.

Glenn, C. B. (2004). Constructing consumables and consent: A critical analysis of factory farm industry discourse. Journal of Communication Inquiry, 28(1), 63-81. http://dx.doi.org/10.1177/0196859903258573.

Grauerholz, L. (2007). Cute enough to eat: The transformation of animals into meat for human consumption in commercialized images. Humanity \& Society, 31(4) 334-354. http://dx.doi.org/10.1177/016059760703100404.

Hardisty, D. J., Johnson, E. J., \& Weber, E. U. (2010). A dirty word or a dirty world?: Attribute framing, political affiliation, and query theory. Psychological Science, 21(1), 86-92. http://dx.doi.org/10.1177/0956797609355572.

Harper, G., \& Henson, S. (2001). Consumer concerns about animal welfare and the impact on food choice. Retrieved from United Kingdom: http://ec.europa.eu research/biosociety/pdf/fair ct98 3678 partb.pdf.

Harper, G., \& Makatouni, A. (2002). Consumer perception of organic food production and farm animal welfare. British Food Journal, 104(3/4/5), 287-299. http:/ dx.doi.org/10.1108/00070700210425723.

Hayes, A. F. (2013). Introduction to mediation, moderation, and conditional process analysis: A regression-based approach. New York, US-NY: Guilford Press.

Heinz, B., \& Lee, R. (1998). Getting down to the meat: The symbolic construction of meat consumption. Communication Studies, 49(1), 86-99. http://dx.doi.org/ $10.1080 / 10510979809368520$.

Hoogland, C. T., de Boer, J., \& Boersema, J. J. (2005). Transparency of the meat chain in the light of food culture and history. Appetite, 45(1), 15-23. http://dx.doi.org/ 10.1016/j.appet.2005.01.010.

Hopkins, P. D., \& Dacey, A. (2008). Vegetarian meat: Could technology save animals and satisfy meat eaters? Journal of Agricultural and Environmental Ethics, 21(6), 579-596. http://dx.doi.org/10.1007/s10806-008-9110-0.

Horberg, E. J., Oveis, C., Keltner, D., \& Cohen, A. B. (2009). Disgust and the moralization of purity. Journal of Personality and Social Psychology, 97(6), 963-976. http://dx.doi.org/10.1037/a0017423.
Joy, M. (2011). Why we love dogs, eat pigs, and wear cows: An introduction to carnism. San Francisco, US-CA: Conari Press.

Kenyon, P. M., \& Barker, M. E. (1998). Attitudes towards meat-eating in vegetarian and non-vegetarian teenage girls in England-an ethnographic approach. Appetite, 30(2), 185-198. http://dx.doi.org/10.1006/appe.1997.0129.

Keren, G. (Ed.). (2011). Perspectives on framing. New York, US-NY: Psychology Press.

Kimel, S. Y., Huesmann, R., Kunst, J. R., \& Halperin, E. (2016). Living in a genetic world: How learning about interethnic genetic similarities and differences affects peace and conflict. Personality and Social Psychology Bulletin, 42(5), 688-700. http://dx.doi.org/10.1177/0146167216642196.

Köster, E. P. (2009). Diversity in the determinants of food choice: A psychological perspective. Food Quality and Preference, 20(2), 70-82.

Krebs, D. (1975). Empathy and altruism. Journal of Personality and Social Psychology, 32(6), 1134-1146. http://dx.doi.org/10.1037/0022-3514.32.6.1134.

Kubberød, E., Ueland, Ø., Tronstad, Å., \& Risvik, E. (2002). Attitudes towards meat and meat-eating among adolescents in Norway: A qualitative study. Appetite, 38(1), 53-62. http://dx.doi.org/10.1006/appe.2002.0458.

Kunst, J. R., Thomsen, L., Sam, D. L., \& Berry, J. W. (2015). “We are in this together”: Common group identity predicts majority members' active acculturation efforts to integrate immigrants. Personality and Social Psychology Bulletin, 41(10), 1438-1453. http://dx.doi.org/10.1177/0146167215599349.

Lakoff, G. (2004). Don't think of an elephant: Progressive values and the framing wars - a progressive guide to action. White River Junction, US-VT: Chelsea Green Publishing.

Leak, G. K., \& Christopher, S. B. (1982). Empathy from an evolutionary perspective. Journal for the Theory of Social Behaviour, 12(1), 79-82. http://dx.doi.org/10.1111/ j.1468-5914.1982.tb00439.x.

Lerner, J. E., \& Kalof, L. (1999). The animal text. Sociological Quarterly, 40(4), 565-586. http://dx.doi.org/10.1111/j.1533-8525.1999.tb00568.x.

Leroy, F., \& Degreef, F. (2015). Convenient meat and meat products. Societal and technological issues. Appetite, 94, 40-46. http://dx.doi.org/10.1016/ j.appet.2015.01.022.

Levin, I. P., \& Gaeth, G. J. (1988). How consumers are affected by the framing of attribute information before and after consuming the product. Journal of Consumer Research, 15(3), 374-378.

Lorenz, K. (1970). Studies in animal and human behaviour. London, United Kingdom: Methuen.

Loughnan, S., Haslam, N., \& Bastian, B. (2010). The role of meat consumption in the denial of moral status and mind to meat animals. Appetite, 55(1), 156-159. http://dx.doi.org/10.1016/j.appet.2010.05.043.

Magdoff, F., Foster, J. B., \& Buttel, F. H. (2000). Hungry for profit: The agribusiness threat to farmers, food, and the environment. New York, US-NY: Monthly Review Press.

Mayfield, L. E., Bennett, R. M., Tranter, R. B., \& Wooldridge, M. J. (2007). Consumption of welfare-friendly food products in Great Britain, Italy and Sweden, and how it may be influenced by consumer attitudes to, and behaviour towards, animal welfare attributes. International Journal of Sociology of Agriculture and Food, 15(3), 59-73.

OECD.. (2014). OECD-FAO agricultural outlook 2014-2023. Retrieved from.

PETA (Producer). (2013). Official "glass walls" video by Paul McCartney [Video file]. Retrieved from: http://www.peta.org/videos/glass-walls-2/.

Phillips, C. (2009). Empathy towards animals. The Welfare of Animals, 47-54. Ebook: Springer.

Piazza, J., Ruby, M. B., Loughnan, S., Luong, M., Kulik, J., Watkins, H. M., et al. (2015). Rationalizing meat consumption. The 4Ns. Appetite, 91, 114-128. http:// dx.doi.org/10.1016/j.appet.2015.04.011.

Preston, S. D., \& de Waal, F. B. M. (2002). Empathy: Its ultimate and proximate bases. Behavioral and Brain Sciences, 25(1), 1-20. http://dx.doi.org/10.1017/ S0140525X02000018.

Rachels, J. (2004). The basic argument for vegetarianism. In S. F. Sapontzis (Ed.), Food for thought: The debate over eating meat (pp. 70-79). Amherst, US-NY: Promotheus Books.

van Rijswijk, W., Frewer, L. J., Menozzi, D., \& Faioli, G. (2008). Consumer perceptions of traceability: A cross-national comparison of the associated benefits. Food Quality and Preference, 19(5), 452-464. http://dx.doi.org/10.1016/ j.foodqual.2008.02.001.

Rogers, R. A. (2008). Beasts, burgers, and hummers: Meat and the crisis of masculinity in contemporary television advertisements. Environmental Communication, 2(3), 281-301. http://dx.doi.org/10.1080/17524030802390250.

Rothgerber, H. (2013). Real men don't eat (vegetable) quiche: Masculinity and the justification of meat consumption. Psychology of Men \& Masculinity, 14(4), 363-375. http://dx.doi.org/10.1037/a0030379.

Rothgerber, H. (2015). Underlying differences between conscientious omnivores and vegetarians in the evaluation of meat and animals. Appetite, 87, 251-258. http://dx.doi.org/10.1016/j.appet.2014.12.206.

Rothgerber, H., \& Mican, F. (2014). Childhood pet ownership, attachment to pets, and subsequent meat avoidance. The mediating role of empathy toward animals. Appetite, 79, 11-17. http://dx.doi.org/10.1016/j.appet.2014.03.032.

Rozin, P., \& Fallon, A. E. (1980). The psychological categorization of foods and nonfoods: A preliminary taxonomy of food rejections. Appetite, 1(3), 193-201. http://dx.doi.org/10.1016/S0195-6663(80)80027-4.

Rozin, P., \& Fallon, A. E. (1987). A perspective on disgust. Psychological Review, 94(1), 23-41. http://dx.doi.org/10.1037/0033-295X.94.1.23.

Ruby, M. B. (2012). Vegetarianism. A blossoming field of study. Appetite, 58(1), 141-150. http://dx.doi.org/10.1016/j.appet.2011.09.019. 
Santos, M. L. S., \& Booth, D. A. (1996). Influences on meat avoidance among British students. Appetite, 27(3), 197-205. http://dx doi.org/10.1006/appe1996.0046.

Serpell, J. (1986). In the company of animals: A study of human-animal relationships. New York, US-NY: Basil Blackwell.

Singer, P. (1995). Animal liberation. Random House.

Stibbe, A. (2001). Language, power and the social construction of animals. Society \& Animals, 9(2), 145-161. http://dx.doi.org/10.1163/156853001753639251.

Toma, L., Stott, A. W., Revoredo-Giha, C., \& Kupiec-Teahan, B. (2012). Consumers and animal welfare. A comparison between European Union countries. Appetite, 58(2), 597-607. http://dx.doi.org/10.1016/j.appet.2011.11.015.
Tybur, J. M., Lieberman, D., \& Griskevicius, V. (2009). Microbes, mating, and morality: Individual differences in three functional domains of disgust. Journal of Personality and Social Psychology, 97(1), 103-122. http://dx.doi.org/10.1037/ a0015474.

Westbury, H. R., \& Neumann, D. L. (2008). Empathy-related responses to moving film stimuli depicting human and non-human animal targets in negative circumstances. Biological Psychology, 78(1), 66-74. http://dx.doi.org/10.1016/ j.biopsycho.2007.12.009.

Zellers, P. (2011, May 26). Mark Zuckerberg's new challenge: Eating only what he kills (and yes, we do mean literally...). Fortune. 